\title{
Intrusion Induced Global Warming Preceding Continental Flood Basalt Volcanism
}

Xiaochuan Tian ( $\nabla$ xtian@ldeo.columbia.edu )

Lamont-Doherty Earth Observatory https://orcid.org/0000-0003-0289-1794

W Buck

Lamont-Doherty Earth Observatory

Physical Sciences - Article

Keywords: tectonics, climate, paleoclimatology, global warming

Posted Date: May 11th, 2021

DOl: https://doi.org/10.21203/rs.3.rs-73857/v1

License: (c) (i) This work is licensed under a Creative Commons Attribution 4.0 International License. Read Full License 
Affiliation:

7 Temporal correlations between continental flood basalt eruptions and mass extinctions

8 have long been recognized ${ }^{1}$. Massive carbon degassing of Large Igneous Provinces can

9 cause catastrophic global climatic and biotic perturbations ${ }^{1-3}$. However, recent high-

10 precision geochronology from the Deccan Traps ${ }^{4,5}$ and the Columbia River Basalt Group ${ }^{6}$

11 challenges this causal link by showing that the major phase of flood basalts eruptions

12 happened after the onset of global warming ${ }^{7-9}$ by several hundred thousand years. Here,

13 we argue that major eruptions of continental flood basalts may require densification of the

14 crust by intrusion of larger volumes of magma than are extruded. Simple models show

15 that magma crystallization and release of $\mathrm{CO}_{2}$ from such intrusions could produce global

16 warming before the main phase of flood basalt eruptions on the observed timescale. Our

17 model, consistent with geological, geophysical, geochemical and paleoclimate data, suggests

18 that the evolving crustal density has a first-order control on timing of the major phase of

19 continental flood basalt volcanism. Degassing of $\mathrm{CO}_{2}$ from LIP-related intrusions

20 significantly affects Earth's climate and habitability. 


\section{Introduction}

By far Earth's largest volcanic eruptions occur during the formation of continental

23 flood basalts that define the surface extent of Large Igneous Provinces (LIPs). Major LIPs

24 typically extrude more than $10^{6} \mathrm{~km}^{3}$ of magma within 1 million years ${ }^{2}$. Estimates of carbon

25 dioxide $\left(\mathrm{CO}_{2}\right)$ concentrations in primitive LIP magma vary from 0.1 to $\sim 2$ weight percent ${ }^{10}$, so

26 that extrusions of a LIP could release as much as $6 \times 10^{16} \mathrm{Kg}$ of $\mathrm{CO}_{2}$. Such fluxes are enough to

27 significantly warm Earth's climate ${ }^{7}$. The emplacement of LIPs are widely recognized to be

28 coeval with climate changes and mass extinctions events ${ }^{1}$. These temporal correlations support

29 the idea that flood basalt eruptions releasing massive amounts of greenhouse gases may cause

30 climatic excursions and biotic crises.

31 Recent studies indicate that for at least two LIPs global warming began several hundred

32 thousand years before the onset of the bulk of volcanism. For the Deccan traps, one of the largest

33 LIPs, new data suggests that $73 \%$ of the flood basalts ${ }^{4,5,11}$ were emplaced $\sim 360$ kyr after the

34 onset of an average $2{ }^{\circ} \mathrm{C}$ global warming and before the Cretaceous-Paleogene $(\mathrm{K} / \mathrm{Pg})$ boundary ${ }^{7}$

35 (Fig. 1a). For the Columbia River Basalt Group (CRBG), volcanic $\mathrm{CO}_{2}$ release is a possible

36 cause of the global warming and ice sheet melting during the Miocene Climate Optimum (MCO;

37 17-14.7 Ma) ${ }^{12}$. However, recent basalt chronology data ${ }^{6}$ indicates that $95 \%$ of the CRBG was

38 erupted after 16.7 Ma, 300 kyr after the onset of $\mathrm{MCO}^{8,9}$ (Fig. 1b). The new data for both the

39 Deccan Traps and the CRBG undermines the hypothetical causal link between LIP volcanism

40 and global warming. 
a Deccan Traps and K/Pg Global Warming

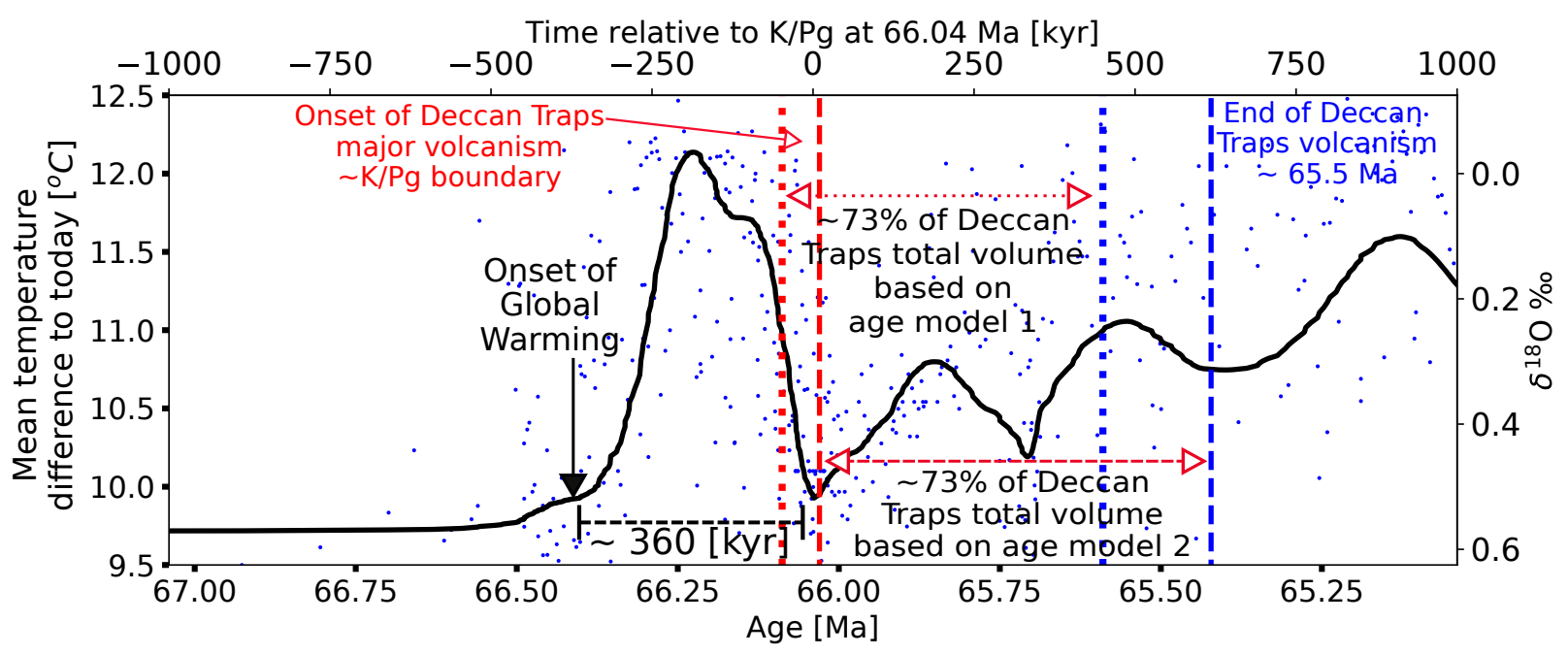

b Columbia River Basalt Group (CRBG) and Miocene Climate Optimum (MCO)

41

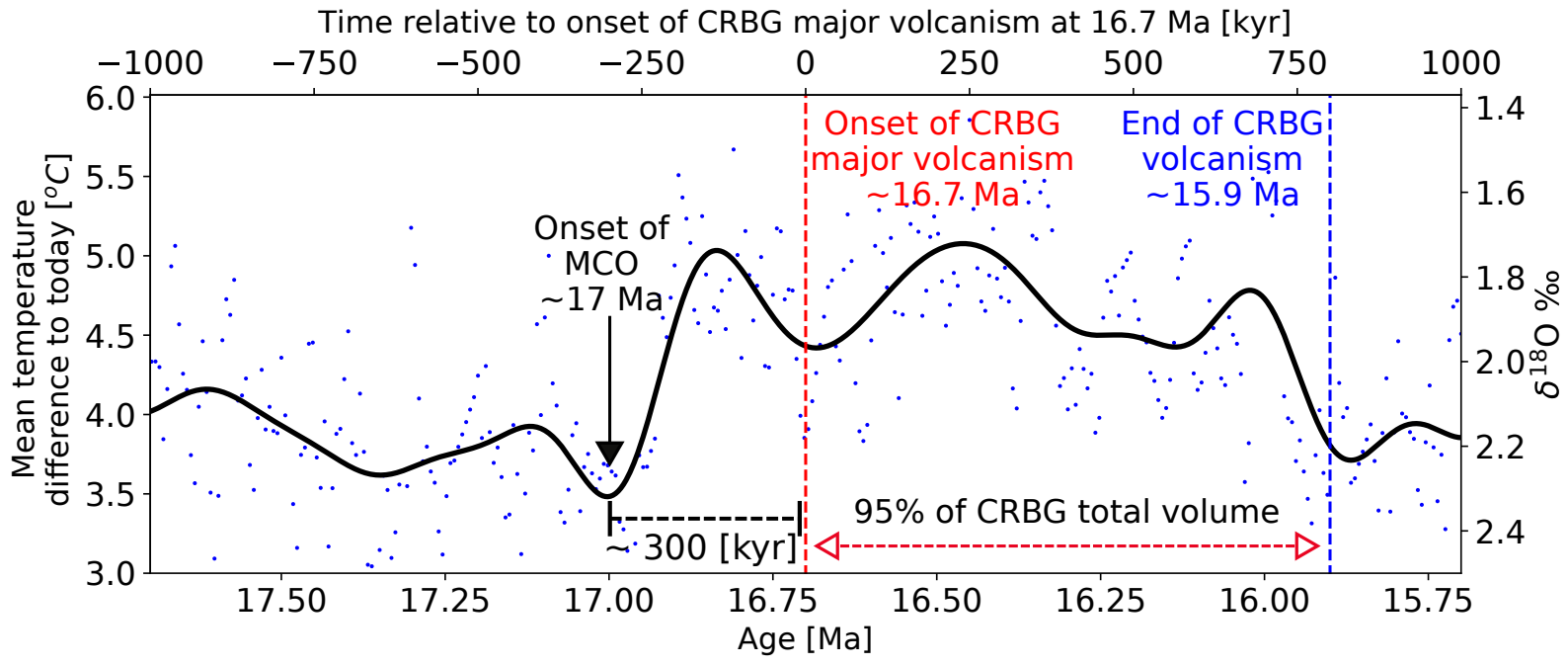

42 Fig 1. Global temperature variations within $1000 \mathrm{kyr}$ of the approximate onset of the main volcanic phases of

43 the Deccan Traps ${ }^{4,5}$ and Columbia River Basalt Group ${ }^{6}$ LIPs. Black lines result from low-pass filtering of the

44 blue dots $\delta^{18} O$ data and estimated temperature variations with time ${ }^{7-9}$. The age of onset and ending of the main

45 Deccan volcanic phase for two basalt dating methods are indicated by the pairs of vertical dashed lines. Vertical

46 arrows indicate that the onset of global warming for each case precedes the main volcanic phase by $\sim 300 \mathrm{kyr}$.

47 Details of the age models and temperature estimates are described in the supplement.

Volcanoes are pathways for magma to reach Earth's surface, but for many volcanoes more magma is intruded than is erupted ${ }^{13-15}$. For continental LIPs, geophysical data indicates that from 3 to 16 times more magma is intruded as is extruded ${ }^{2,16,17}$. For example, below the 
51 Deccan Traps and the CRBG higher-than-normal seismic velocities may indicate voluminous

52 mafic crustal intrusions ${ }^{18-20}$. Geochemical studies of the CRBG also indicate up to $85 \%$ of total 53 magma volume was emplaced within the crust ${ }^{21}$.

54 Crystallization releases nearly all carbon dioxide dissolved in basaltic magma ${ }^{22,23}$. Gas

55 released from solidifying intruded magma should traverse the overlying crust through fractures,

56 faults and hydrothermal vents ${ }^{24}$, as inferred for Yellowstone ${ }^{25}$ or the East African Rift ${ }^{26}$. Thus,

57 the intrusion and solidification of millions of cubic kilometers of basaltic LIP magma would

58 release far more $\mathrm{CO}_{2}$ than released by extrusion. If the intrusion precedes extrusion it would

59 explain the pattern of global warming preceding LIP surface flows.

Geochemical studies indicate that mantle-derived magma resides for thousands of years

61 in transcrustal magmatic systems before it extrudes ${ }^{27}$. For extrusion, the pressure in such magma

62 reservoirs must be greater than the hydrostatic pressure at the base of a column of magma from

63 the surface to the reservoirs. The long-term average pressure in a magma reservoir should equal

64 the lithostatic pressure (the average density of the overlying crust times the acceleration of

65 gravity and the depth below the surface). Magma reservoirs can be 'overpressured' relative to

66 lithostatic pressure, but it is difficult to maintain overpressure if magma reservoirs are large

67 and/or are surrounded by low viscosity crust ${ }^{28,29}$. For many LIPs crustal intrusions are thought

68 to be very large, with lateral dimensions up to $\sim 10^{3}$ kilometers ${ }^{17,20,30}$ so that overpressures

69 should be negligible. Thus, large flood basalt extrusions may only happen when the average

70 overburden density is greater than the magma density.

71 Particularly clear evidence for the importance of crustal density in controlling eruptions

72 comes from plate spreading centers. Constraints on the depth of axial magma chambers (AMCs)

73 and the crustal density structure at oceanic spreading centers are superior to those for continental 
74 magma bodies due to the greater resolving power of marine seismic methods. AMCs are fairly

75 small ( $\sim 1 \mathrm{~km}$ wide) and are seen to lie at or below the depth where the average overburden

76 density equals magma density, a depth that is termed the 'level of eruptibility' ${ }^{31,32}$.

77 Continental crustal density generally increases with depth and so the average density of

78 overburden also increases with depth. Figure 2a shows the average seismic compressional wave

79 velocities in continental crust with depth based on global seismic experiments ${ }^{33}$. Assuming a

80 standard relation between seismic velocity and density for crustal rocks at different depths ${ }^{33}$, we

81 infer the average crustal density structure based on the seismic velocities. Upper continental

82 crust is composed of felsic rocks rich in low density minerals like quartz and feldspar while the

83 lowermost crust is less felsic and so denser. Assuming a typical basaltic magma density of 2800

$84 \mathrm{~kg} \mathrm{~m}^{-3}$ and a crustal density structure shown in Fig. 2a there should be enough pressure for

85 eruptions only if the magma is sourced from reservoirs like sills that are deeper than the level of

86 eruptibility at $27 \mathrm{~km}$ (Fig. $2 \mathrm{~b}$ red). For sills at shallower depths (Fig. $2 \mathrm{~b}$ blue) the magma should

87 not reach the surface even with an open conduit to the surface. 

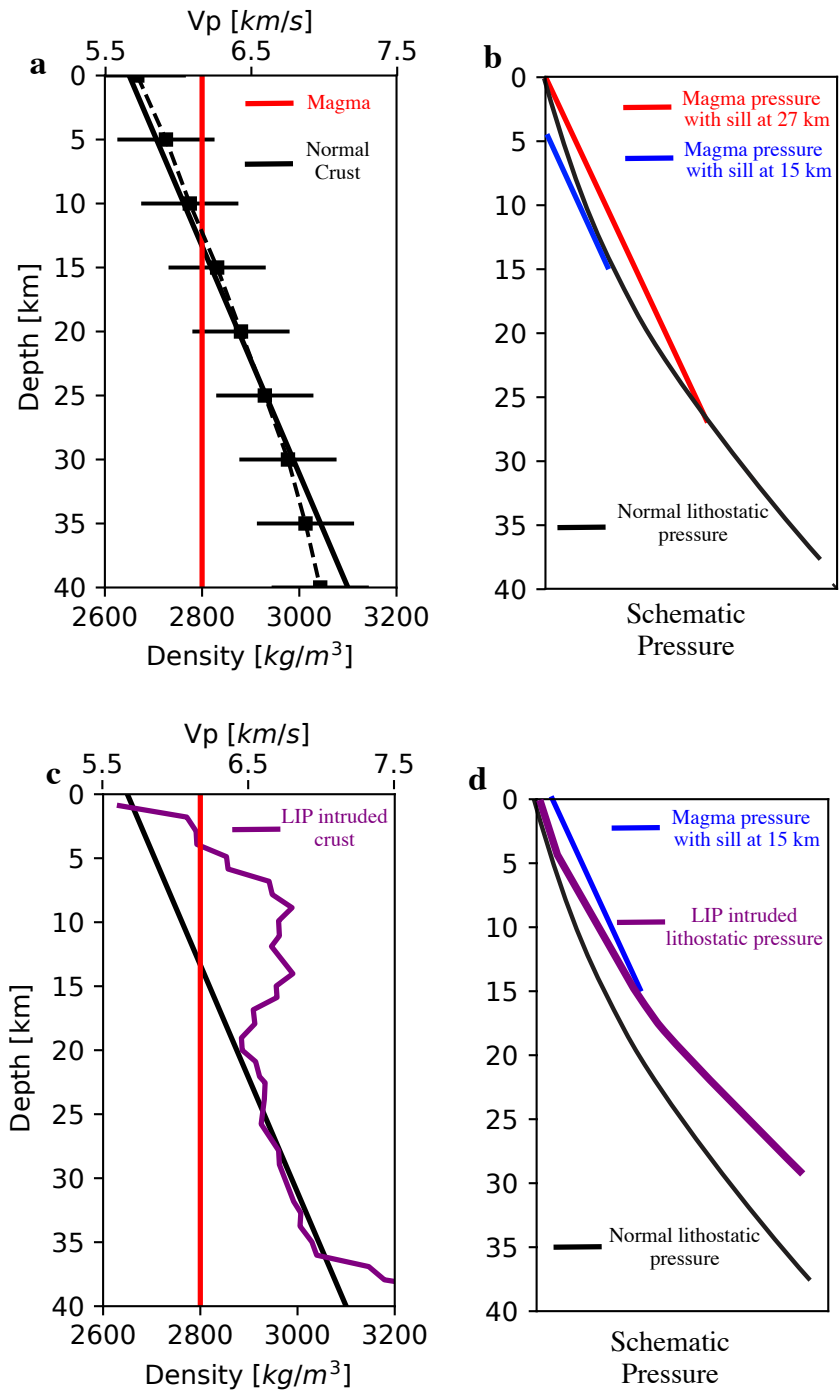

Fig. 2 | Illustrations of relations between seismic velocities, densities and pressures in typical continental crust

90 (a,b) and the crust under part of the Deccan LIP (c,d). a, shows average continental P-wave velocity (dashed)

91 from ref ${ }^{33}$ with density assuming a linear relation between velocity and density. Solid lines show densities assumed

92 in the model. Magma density is from ref. ${ }^{34} . \mathbf{b}$, black line shows lithostatic pressure for the density structure given

93 by solid line in a. Red line shows static pressure in a column of magma just reaching the surface while blue shows

94 the same for a column of magma with lithostatic pressure at $15 \mathrm{~km}$ depth. $\mathbf{c}$, P-wave velocity and density profiles

95 beneath Deccan Traps are converted from refs. ${ }^{18,19}$ using a Vs to Vp relationship (ref. ${ }^{35}$ ). d, Purple line shows

96 lithostatic pressure for the purple density from c. Blue line shows that for densified crust a sill as shallow as $15 \mathrm{~km}$

97 depth can supply eruptions. Schematic pressure is shown so the difference between lithostatic pressure and magma

98 pressure is visible. 
Seismic velocities and densities beneath several LIPs are significantly higher than for

100 typical continental crust. Figure 2c shows estimated compressional wave velocities based on a

101 profile of crustal shear velocities beneath Deccan Traps ${ }^{18,19,35}$. Applying a standard velocity to

102 density conversion ${ }^{33}$, we find that the densities of the upper crust are markedly greater than that

103 of average crust (Fig. 2c). Such an upper crustal density structure means that magma from sills

104 as shallow as $\sim 10 \mathrm{~km}$ should be able to erupt. The denser crust of LIPs is likely due to basaltic 105 crustal intrusions ${ }^{18,19}$.

106 We suggest that crustal densification due to voluminous magma intrusion and

107 solidification is necessary to allow extrusion of continental flood basalts. The massive magma

108 flux for a LIP is thought to originate in active upwellings of hotter-than-normal mantle ${ }^{36}$. Partial

109 melting occurs as mantle rises and pressure decreases. The short duration of LIP magmatic

110 events indicates that the plume-induced melt flux increases and then decreases on a time scale

111 shorter than a few million years. The heat from the magma enables an intruded sill to heat up the

112 overlying crust and allows rapid decrease in the intrusion depth during the phase of flux increase.

113 As the melt flux wanes the crust above a sill should cool and the sill intrusion depth deepens.

114 Through this shallowing and deepening cycle, dense solidified mafic intrusions are emplaced

115 into the crust, shifting the level of eruptibility.

116 Precise controls on sill opening depths are controversial, but temperature structure is

117 almost certain to be a critical factor. Temperature affects the strength of rocks that must be

118 deformed to allow opening. Temperature structure also controls the rate of cooling of magma in

119 sills. Both effects mean that the hotter the crust, the shallower the minimum depth of sill

120 opening. Analytic relations between the heat released from intrusion and the steady-state

121 temperature structure of the crust, described in the Methods, show that reasonable magma flux 
122 variations can produce the kinds of changes in sill depth required to cause extrusion late in the 123 emplacement of a LIP.

124 Because crustal thermal structure does not respond instantaneously to changes in 125 magmatic heat input, we need a time-dependent model that includes diffusion and advection of 126 heat as well as reasonable assumptions about controls on sill depth. The key question to test is 127 whether a model can produce a major phase of extrusion starting a few hundred thousand years 128 after the onset of detectable global warming that is caused by the $\mathrm{CO}_{2}$ degassed from the 129 preceding crustal magma intrusions.

130 Here we discuss a numerical model that builds on a recent 'multi-sill' approach ${ }^{37}$. The 131 model assumes that Moho level magma reservoirs ${ }^{28}$ feed crustal sill intrusions. A new feature of 132 our model is that it explicitly determines the depth of each sill intrusion based on how earlier 133 sills change the thermal and compositional structure of the crust. The onset of a shift of LIP 134 magma emplacement from mostly intrusion to mostly large volume eruptions is assumed to be 135 established when two necessary conditions are met: first, the overburden of an active sill is on 136 average denser than melt; second, the upward migrating magma from the Moho-level reservoir 137 and the active sill is not intruded laterally before reaching the surface. The model also assumes 138 that the magma flux follows a Gaussian function in time and that magma solidifies shortly after 139 emplacement. This solidification releases most $\mathrm{CO}_{2}$ dissolved in the magma into the atmosphere. 140 A standard Long-term Ocean-atmosphere-Sediment CArbon cycle Reservoir Model (LOSCAR)

$141{ }^{38}$ is used to compute the effect of this $\mathrm{CO}_{2}$ flux on global temperatures (see Methods for details).

\section{Results}


145 the intruded region. As the melt supply increases, sills intrude at progressively shallower depths.

146 The average density of the overburden of the intruding sills remains less than the magma density,

147 so there are no major eruptions. Meanwhile, $\mathrm{CO}_{2}$ exsolves from the cooling and solidifying melt

148 and is added to the atmosphere.

149 Between stages one and two, a series of sills are emplaced upwards between 'sill 1' and

150 'sill 2' as melt flux increases. Significant heat is added to the crust at regions with sill intrusions.

151 Again, there is no eruption at this time as the average density of the overburden is still less than

152 that of magma. At stage three, as a series of sills are intruded into the mid-to-upper crust,

153 hydrothermal circulation that transports heat to the surface increases its vigor due to the higher

154 thermal gradient and permeability resulting from fractures induced by sill intrusions. However,

155 the magma flux begins to decrease. Sill intrusions cannot exist shallower than the depth where

156 heat lost to the surface is sustained by heat input from sill intrusions. Still no eruptions occur

157 because the density of magma is still greater than the depth-averaged density of crust above the

158 intruding sill.

After several hundred thousand years of intrusion, the magma supply wanes while

160 hydrothermal circulation is still vigorous. The intruded upper crust cools, solidifies and becomes

161 denser and stronger. The resistance to sill intrusion increases at shallow depths. At this point

162 (stage four), sills intrude deeper into the hotter and weaker crust (Fig.3 'sill 4'). The average

163 overburden density is now higher than that of fluid magma. With the densified and stronger crust

164 preventing lateral intrusions above the active sill, magma from the intruding sill can directly

165 erupt to the surface. 

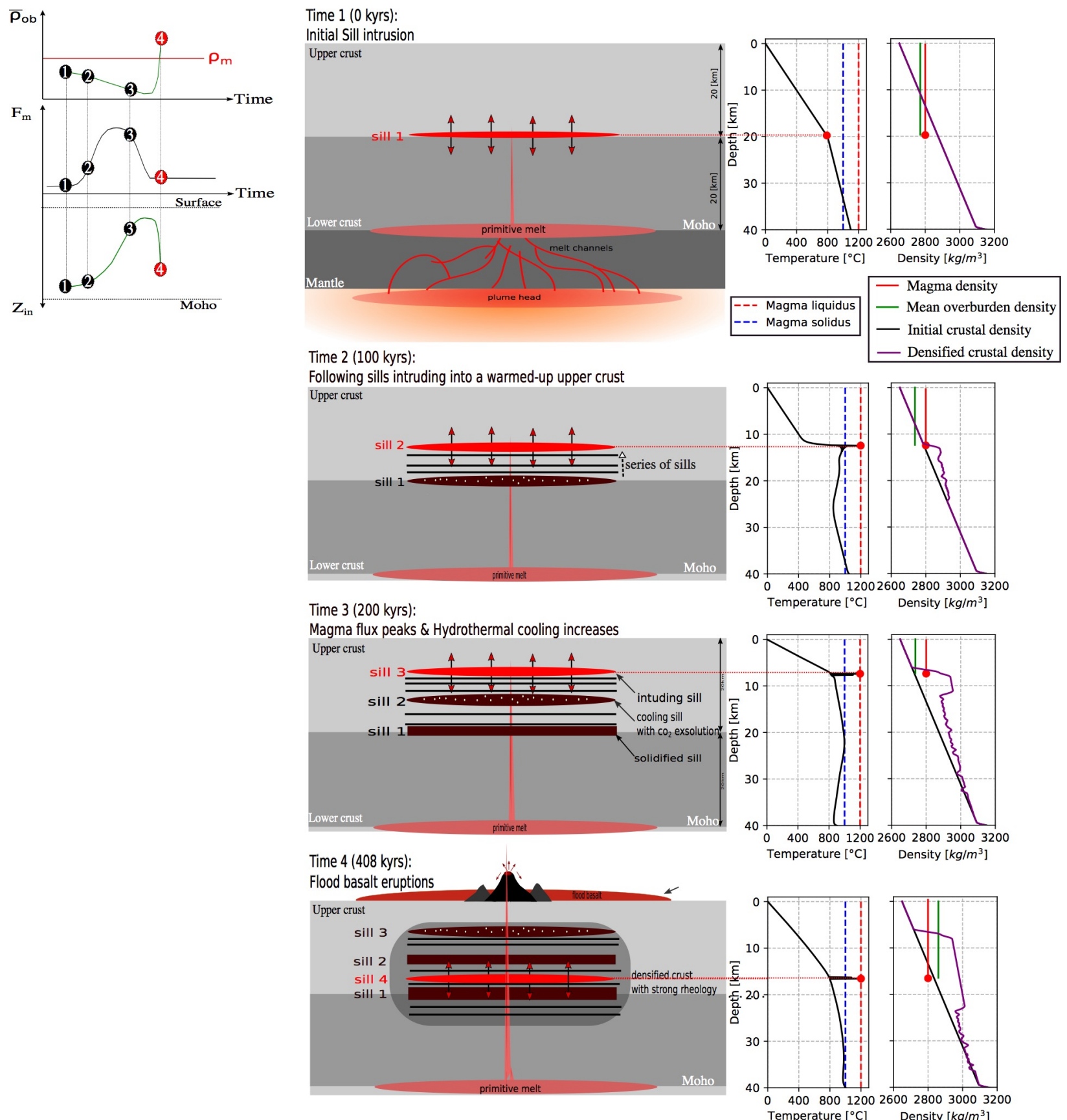

167 Fig. 3 | One dimensional thermo-mechanical model results showing the changes in crustal temperatures and

168 densities due to evolving sill intrusions. $Z_{i n}$ is intrusion depth, $F_{m}$ is magma flux, $\overline{\rho_{o b}}$ is average density of the 169 overburden and $\rho_{m}$ is magma density. The numbers 1 to 4 correspond to the stages of the system developments 170 described in the text. 
The time lag between the onset of predicted warming and the main extrusive phase

172 depends on several model parameters, including: the magma flux through time; the radius of

173 magma sills; the initial thermal, compositional and density structures of the crust and the

174 efficiency of hydrothermal heat transport in the shallow crust. Without assuming vigorous

175 effective hydrothermal cooling of the shallow crust, the modeled time lag between intrusive and

176 extrusive onsets is longer than observed. Figure 4abc show results from one model run that

177 predicts a global warming signal similar to that seen for the Deccan Traps. The coupled

178 LOSCAR model indicates that the intrusive $\mathrm{CO}_{2}$ initiates a $\sim 2$ degrees global warming $300 \mathrm{kyr}$

179 before the major phase of LIP volcanism. By lowering the maximum intrusion flux from 15 to 10

$180 \mathrm{~cm} / \mathrm{yr}$, increasing the upper crustal thermal gradient by $5 \mathrm{~K} / \mathrm{km}$ and increasing the rate of

181 advective cooling by $20 \%$, Figure 4def show results that fit the CRBG and MCO case.

Modeled Results for

Deccan Trap and Climate around $\mathrm{K} / \mathrm{Pg}$
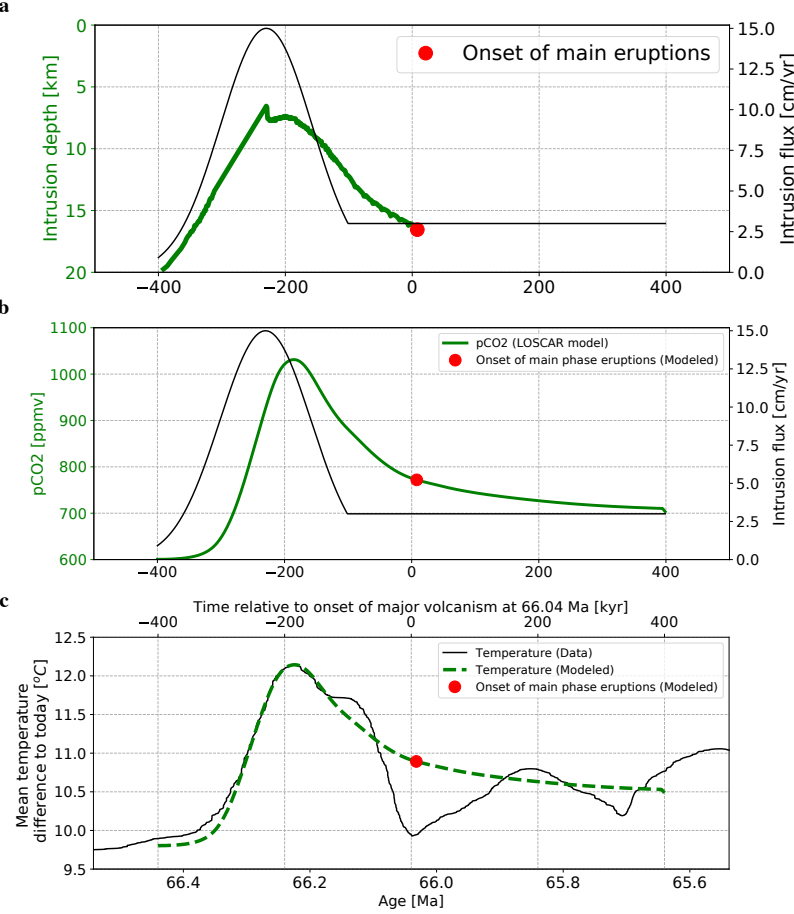

Modeled Results for $\mathrm{CRBG}$ and $\mathrm{MCO}$
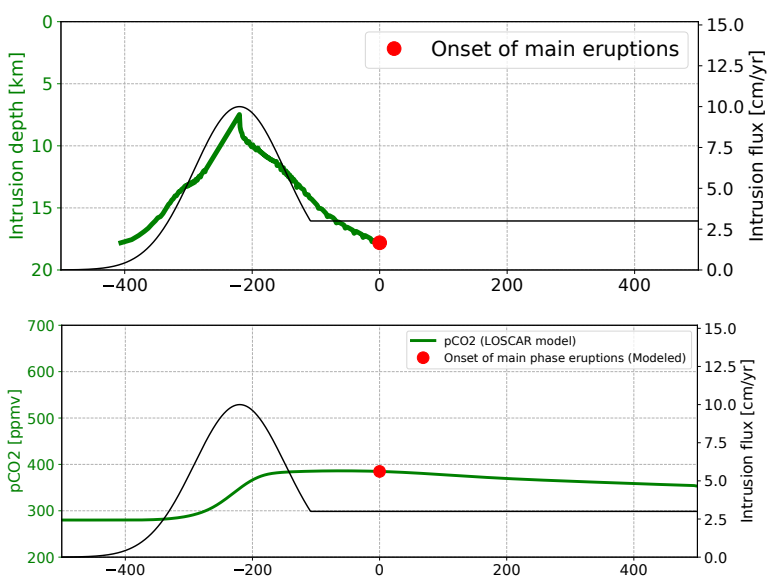

$\mathbf{f}$

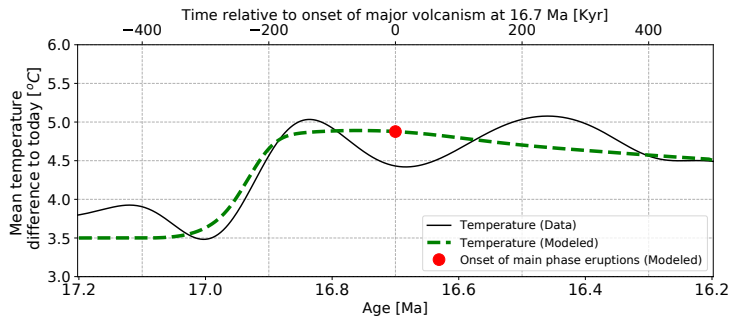



Traps (abc) and CRBG (def). a,d sill intrusion depth and the timing of transition from mostly intrusion to major phase of extrusion, predicted by the thermo-mechanical model described in the Methods, given the indicated melt flux with time. CRBG case (d) has a lower peak flux of $10 \mathrm{~cm} / \mathrm{yr} \mathbf{b}, \mathbf{e}$, global averaged atmospheric $\mathrm{CO}_{2}$ concentration with time predicted by the LOSCAR climate model. c,f global temperature change predicted by the LOSCAR model on top of climate data (Fig.1) and with the modeled timing of onsets of main-phase eruptions.

\section{Discussion}

Our model suggests that intrusion-induced densification of the continental crust may be necessary for large-scale flood basalt eruptions. Massive $\mathrm{CO}_{2}$ degassing from the solidifying

192 intrusions can cause global warming. This provides an explanation for the decoupled climate 193 signal and flood basalt flux. It could also help explain why the main phase of several mass 194 extinctions predates the onset of their related LIP eruptions ${ }^{39}$. magma crystalizes is supported by recent melt inclusion studies of LIP lavas which indicates 197 mid-to-lower crustal exsolution of abundant $\mathrm{CO}_{2}{ }^{23,40}$. Another requirement of the model is that 198 magma sill intrusions should migrate upwards and downwards within several hundred thousand 199 years to densify the crust and induce the state shift ${ }^{41}$ of magma emplacements. That even modest sized mantle plumes can produce shallow magma emplacement is evidenced by seismic 201 data indicating a large volume of partially molten crust less than $10 \mathrm{~km}$ below Yellowstone, 202 where high heat flux, up to $2000 \mathrm{mWm}^{-2}$, is also reported ${ }^{25}$. Petrological and geochemical constraints, though not formally considered in the model, 204 appear broadly consistent with our results. Analysis of the lavas of the Deccan Traps, the CRBG 205 and some other LIPs reveal common trends of decreasing crustal contamination with time ${ }^{11,21,41-}$ $206{ }^{45}$. We speculate that the earlier lavas were sourced from crustal sills where mantle melt mixed 
207 with continental crust, showing higher degrees of crustal contamination. In contrast, the main

208 phase of volcanism was largely sourced directly from the deeper mantle melt reservoir, from

209 which the magma traversed the densified and strengthened crust relatively rapidly without much

210 interaction and hence having a stronger mantle signature ${ }^{11,45}$.

211 Many previous studies assume the main climatic effect of LIPs results from the carbon

212 dioxide liberated by surface lava flows. Because the volume of $\mathrm{CO}_{2}$ released directly from such

213 flood basalts may be less than is needed to produce observed increases in global temperatures,

214 several groups invoke sources of extra carbon including 'cryptic' degassing ${ }^{46}$ either by sill

215 intrusion heating of carbon-rich sedimentary strata ${ }^{24}$ or by a carbon-rich plume melting and

216 releasing $\mathrm{CO}_{2}$ deep in the mantle ${ }^{47}$. However, besides requiring high carbon concentrations,

217 these models either have not quantified the climatic response of the $\mathrm{CO}_{2}$ release or do not explain

218 the time lag between the global warming and the major eruption phase. As noted earlier, the

219 volume of magma intruded deep in the crust during LIP formation may be an order of magnitude

220 greater than that reaching the surface. Thus, the $\mathrm{CO}_{2}$ released from those deep intrusions may be

221 the main driver of the observed global warming and associated extinction events.

222 Magmatic processes are undeniably far more complex than the crude models considered

223 here. The detailed processes of cooling, solidification and $\mathrm{CO}_{2}$ degassing from large-scale crustal

224 magma intrusions and mechanism for controlling eruption tempo of a LIP are beyond the scope

225 of this study. We do not intend to fit the climate and extrusive data with our simple model. We

226 merely try to provide a simple, physically-based model to show that reasonable changes in the

227 thermal and density structures of the crust during massive magmatic events could lead to most

228 intrusion happening before the major phase of continental flood basalt extrusions. Our results 
229 support the idea that $\mathrm{CO}_{2}$ from LIP intrusives is one of the main drivers of the rapid climate 230 changes causing mass extinctions.

231 
233 1. Courtillot, V.E. \& Renne, P. R. On the ages of flood basalt events. Comptes Rendus

234 Geosci. 335, 113-140 (2003).

235 2. Coffin, M. F. \& Eldholm, O. Large igneous provinces: Crustal structure, dimensions, and 236 external consequences. Rev. Geophys. 32, 1 (1994).

237 3. Jones, M. T., Jerram, D. A., Svensen, H. H. \& Grove, C. The effects of large igneous 238 provinces on the global carbon and sulphur cycles. Palaeogeogr. Palaeoclimatol.

$239 \quad$ Palaeoecol. 441, 4-21 (2016).

240 4. Sprain, C. J. et al. The eruptive tempo of Deccan volcanism in relation to the Cretaceous241 Paleogene boundary. Science (80-. ). 363, 866-870 (2019).

242 5. Schoene, B. et al. U-Pb constraints on pulsed eruption of the Deccan Traps across the end243 Cretaceous mass extinction. Science (80-. ). 363, 862-866 (2019).

244 6. Kasbohm, J. \& Schoene, B. Rapid eruption of the Columbia River flood basalt and 245 correlation with the mid-Miocene climate optimum. Sci. Adv. 4, eaat8223 (2018).

246 7. Hull, P. M. et al. On impact and volcanism across the Cretaceous-Paleogene boundary. 247 Science (80-. ). 367, 266-272 (2020).

248 8. Holbourn, A., Kuhnt, W., Kochhann, K. G. D., Andersen, N. \& Sebastian Meier, K. J. 249 Global perturbation of the carbon cycle at the onset of the Miocene Climatic Optimum. $250 \quad$ Geology 43, 123-126 (2015).

251 9. Westerhold, T. et al. An astronomically dated record of Earth's climate and its 252 predictability over the last 66 million years. Science (80-. ). 369, 1383-1387 (2020).

253 10. Black, B. A. \& Gibson, S. A. Deep Carbon and the Life Cycle of Large Igneous Provinces. 254 Elements 15, 319-324 (2019). 
255 11. Richards, M. A. et al. Triggering of the largest Deccan eruptions by the Chicxulub impact. 256 Geol.Soc. Am. Bull. 127, 1507-1520 (2015).

257 12. Holbourn, A., Kuhnt, W., Kochhann, K. G. D., Andersen, N. \& Sebastian Meier, K. J. 258 Global perturbation of the carbon cycle at the onset of the Miocene Climatic Optimum. $259 \quad$ Geology 43, 123-126 (2015).

260 13. Townsend, M., Huber, C., Degruyter, W. \& Bachmann, O. Magma Chamber Growth 261 During Intercaldera Periods: Insights From Thermo-Mechanical Modeling With Applications to Laguna del Maule, Campi Flegrei, Santorini, and Aso. Geochemistry,

264 14. Ward, K. M., Zandt, G., Beck, S. L., Christensen, D. H. \& McFarlin, H. Seismic imaging 265 of the magmatic underpinnings beneath the Altiplano-Puna volcanic complex from the

15. White, S. M., Crisp, J. A. \& Spera, F. J. Long-term volumetric eruption rates and magma budgets. Geochemistry, Geophys. Geosystems 7, 1-2 (2006).

270

16. Crisp, J. A. Rates of magma emplacement and volcanic output. J. Volcanol. Geotherm. Res. 20, 177-211 (1984).

272 17. Ridley, V. A. \& Richards, M. A. Deep crustal structure beneath large igneous provinces and the petrologic evolution of flood basalts. Geochemistry, Geophys. Geosystems 11, Q09006 (2010).

275 18. Sen, G. \& Chandrasekharam, D. Deccan Traps Flood Basalt Province: An evaluation of 276 the thermochemical plume model. In Topics in igneous petrology (pp. 29-53). in Topics in 277 Igneous Petrology 29-53 (Springer, Dordrecht, 2011). 
278 19. Pandey, O. P. Deccan trap volcanic eruption affected the Archaean Dharwar craton of 279 southern India: Seismic evidences. J. Geol. Soc. India 72, 510-514 (2008).

280 20. Catchings, R. D. \& Mooney, W. D. Crustal structure of the Columbia Plateau: Evidence 281 for continental rifting. J. Geophys. Res. Solid Earth 93, 459-474 (1988).

282 21. Moore, N. E., Grunder, A. L. \& Bohrson, W. A. The three-stage petrochemical evolution 283 of the Steens Basalt (southeast Oregon, USA) compared to large igneous provinces and $284 \quad$ layered mafic intrusions. Geosphere 14, 2505-2532 (2018).

285 22. Rosenthal, A., Hauri, E. H. \& Hirschmann, M. M. Experimental determination of C, F, 286 and $\mathrm{H}$ partitioning between mantle minerals and carbonated basalt, $\mathrm{CO} 2 / \mathrm{Ba}$ and $\mathrm{CO} 2$ /Nb systematics of partial melting, and the $\mathrm{CO} 2$ contents of basaltic source regions. Earth 288 Planet. Sci. Lett. 412, 77-87 (2015).

289 23. Capriolo, M. et al. Deep CO2 in the end-Triassic Central Atlantic Magmatic Province. Nat. $290 \quad$ Commun. 11, 1670 (2020).

291 24. Svensen, H. et al. Release of methane from a volcanic basin as a mechanism for initial $292 \quad$ Eocene global warming. Nature 429, 542-545 (2004).

293 25. Huang, H.-H. et al. The Yellowstone magmatic system from the mantle plume to the 294 upper crust. Science (80-. ). 348, 773-776 (2015).

295 26. Lee, H. et al. Massive and prolonged deep carbon emissions associated with continental 296 rifting. Nat. Geosci.9, 145-+ (2016).

297 27. Mutch, E. J. F., Maclennan, J., Holland, T. J. B. \& Buisman, I. Millennial storage of near298 Moho magma. Science (80-. ). 365, 260-264 (2019).

299 28. Karlstrom, L. \& Richards, M. On the evolution of large ultramafic magma chambers and 300 timescales for flood basalt eruptions. J. Geophys. Res. Solid Earth 116, B08216 (2011). 
301 29. Black, B. A. \& Manga, M. Volatiles and the tempo of flood basalt magmatism. Earth 302 Planet. Sci. Lett. 458, 130-140 (2017).

303 30. Ernst, R. E., Liikane, D. A., Jowitt, S. M., Buchan, K. L. \& Blanchard, J. A. A new

304 plumbing system framework for mantle plume-related continental Large Igneous

305 Provinces and their mafic-ultramafic intrusions. J. Volcanol. Geotherm. Res. 384, 75-84

$306 \quad$ (2019).

307 31. Hooft, E. E. \& Detrick, R. S. The role of density in the accumulation of basaltic melts at 308 mid-ocean ridges. Geophys. Res. Lett. 20, 423-426 (1993).

309 32. Buck, W. R., Carbotte, S. M. \& Mutter, C. Controls on extrusion at mid-ocean ridges. $310 \quad$ Geology 25, 935 (1997).

311 33. Christensen, N. I. \& Mooney, W. D. Seismic velocity structure and composition of the continental crust: a global view. J. Geophys. Res. 100, 9761-9788 (1995).

313 34. Stolper, E. \& Walker, D. Melt density and the average composition of basalt. Contrib. to Mineral. Petrol. 74, 7-12 (1980).

315 35. Brocher, T. M. Empirical Relations between Elastic Wavespeeds and Density in the 316 Earth's Crust. Bull. Seismol. Soc. Am. 95, 2081-2092 (2005).

317 36. White, R. S. \& McKenzie, D. Mantle plumes and flood basalts. J. Geophys. Res. Solid 318 Earth 100, 17543-17585 (1995).

319 37. Annen, C., Blundy, J. D. \& Sparks, R. S. J. The Genesis of Intermediate and Silicic 320 Magmas in Deep Crustal Hot Zones. J. Petrol. 47, 505-539 (2006).

321 38. Zeebe, R. E., Zachos, J. C.\& Dickens, G. R. Carbon dioxide forcing alone insufficient to 322 explain Palaeocene-Eocene Thermal Maximum warming. Nat. Geosci. 2, 576-580 (2009).

323 39. Wignall, P. B. Large igneous provinces and mass extinctions. Earth-Science Rev. 53, 1-33 
(2001).

325 40. Hernandez Nava, A. et al. Reconciling early Deccan Traps CO 2 outgassing and pre-KPB global climate. Proc. Natl. Acad. Sci. 118, e2007797118 (2021).

327 41. Renne, P. R. et al. State shift in Deccan volcanism at the Cretaceous-Paleogene boundary, 328 possibly induced by impact. Science (80-. ). 350, 76-78 (2015).

329 42. Yu, X., Lee, C. T. A., Chen, L. H. \& Zeng, G. Magmatic recharge in continental flood 330 basalts: Insights from the Chifeng igneous province in Inner Mongolia. Geochemistry, Geophys. Geosystems 16, 2082-2096 (2015).

332 43. Beane, J. E., Turner, C. A., Hooper, P. R., Subbarao, K. V. \& Walsh, J. N. Stratigraphy, 333 334 composition and form of the Deccan Basalts, Western Ghats, India. Bull. Volcanol. 48, $61-83$ (1986).

335 44. Vanderkluysen, L., Mahoney, J. J., Hooper, P. R., Sheth, H. C. \& Ray, R. The Feeder 336 System of the Deccan Traps (India): Insights from Dike Geochemistry. J. Petrol. 52, 315$337 \quad 343(2011)$.

338 45. Basu, A. R., Saha-Yannopoulos, A. \& Chakrabarty, P. A precise geochemical volcano339 stratigraphy of the Deccan traps. Lithos 376-377, 105754 (2020).

340 46. Armstrong McKay, D. I., Tyrrell, T., Wilson, P. A. \& Foster, G. L. Estimating the impact 341 of the cryptic degassing of Large Igneous Provinces: A mid-Miocene case-study. Earth Planet. Sci. Lett. 403, 254-262 (2014).

343 47. Sobolev, S. V. et al. Linking mantle plumes, large igneous provinces and environmental catastrophes. Nature 477, 312-316 (2011). 
To consider the timing between flood-basalt volcanism and global climate response due

348 to emplacement of a Large Igneous Province (LIP), we develop two versions of a thermo-

349 mechanical sill intrusion model. For a given variable magma flux with initial crustal thermal,

350 density and compositional structures, these models estimate temporal changes of the density and

351 thermal structure of continental crust. These changes govern the predicted onset of the major

352 phase of flood basalt volcanism. The model $\mathrm{CO}_{2}$ degassing flux is then used as an input variable

353 to the Long-term Ocean-atmosphere-Sediment CArbon cycle Reservoir Model (LOSCAR) ${ }^{38,48}$

354 for its climatic response.

As described in the main text, a key assumption of the model is that the initiation of the

356 major phase of flood basalt volcanism is declared when two conditions are met: first, the

357 overburden of an active sill is on average denser than melt; second, the upward migrating magma

358 from the shallowest active sill is not intruded laterally before reaching the surface. The first

359 condition is determined by the crustal density structure and the depth of the intruding sill and the

360 second condition is controlled by the thermo-mechanical state of the crust.

361 A sill intrusion of basaltic magma into continental crust affects both the thermo-

362 mechanical state and density structure of the crust, which further affects where the following sill

363 intrusions are most likely to happen and whether the two necessary conditions are met for large-

364 scale flood basalt eruptions to occur. Here we first give details of a simplified analytic model and

365 then a more complex multi-sill model that treat such intrusion-related crustal changes. The

366 purpose of these models is to assess whether a model with reasonable assumptions and parameter

367 values can produce significant magma intrusion followed by flood basalt eruption several

368 hundred thousand years later. A key output is the predicted time lag between the onset of 
369 significant global warming signal related to $\mathrm{CO}_{2}$ release from solidifying magma intrusion and

370 the onset of major phase of flood basalt extrusion. Before describing the simplified analytic

371 model and the more complex multi-sill model we describe the assumptions and parameter values

372 common to both approaches.

373

\section{Common Model Features}

375 One-dimensional Thermal Model

376 We treat crustal magma emplacement as numerous discrete basaltic sill intrusions similar

377 to previous models ${ }^{37,49}$. We assume that each magma sill is emplaced instantly at its liquidus

378 temperature and only account for the vertical transfer of heat, mass and stress. The assumption of

379 instant emplacement is reasonable because thermal diffusion is much slower than the

380 propagation of a sill intrusion. Only considering the changes in vertical $z$-axis direction is

381 justifiable when a sill has a lateral dimension much larger than its thickness and depth so that the

382 lateral heat transport is negligible. This wide but thin geometry of sills also allows us to neglect

383 flexural response due to the loads of intrusions, which is small when compared to vertical

384 movement of isostatic adjustment. The initial crustal thickness is taken to be close to the global

385 average of $40 \mathrm{~km}^{33}$. The surface is always kept at $0{ }^{\circ} \mathrm{C}$. Convection of water through pore

386 spaces in the shallow crust is considered to enhance heat transfer and we follow other workers

387 (refs. ${ }^{50,51}$ ) who approximate this effect by taking the effective conductivity of the crust to be

388 multiplied by a factor $N u$ (after the Nusselt number for steady-state convection).

389 The evolution of temperatures with depth and time $t$ are described by the one-

390 dimensional heat equation:

391

$$
\frac{\partial T(z, t)}{\partial t}=N u(z, t) \kappa \frac{\partial^{2} T}{\partial z^{2}}-v(t) \frac{\partial T}{\partial z}+\frac{H_{m}}{\rho(z) C_{p}}
$$


392 where $T(z, t)$ is temperature as a function of depth $z$ (positive downward) and time $t, N u(z, t)$ is

393 a dimensionless pre-factor describing enhanced heat transfer efficiency as a function of depth $z$

394 and time $t$, thermal diffusivity $\kappa=10^{-6}\left[\mathrm{~m}^{2} / \mathrm{s}\right], v(t)$ is the downward advection velocity of

395 crust beneath the intruding sill and is equal to the sill thickening rate $F_{m}(t)$ which is also the

396 magma supply flux per unit area. $H_{m}$ with a unit of $\left[\mathrm{W} / \mathrm{m}^{3}\right]$ is the heat liberation or storage rate

397 which accounts for heat liberated on cooling and solidification of basaltic melt and heat stored on

398 melting of solid basalt. $\rho(z)$ is density and $C_{p}=1400[\mathrm{~J} /(\mathrm{kg} \cdot \mathrm{K})]$ is specific heat. The magma

399 in sills is assumed to solidify shortly after emplacement as the time scale for thermal diffusion of

400 a hundred-meters-thick sill is two orders of magnitude shorter than the observed time lag

401 between onsets of warming and eruption. Here, for simplicity, we ignore the crustal radiogenic

402 heat production.

403 Assumed Magma Flux

404 The flux of magma added to the crust is taken to vary in time according to a Gaussian

405 function with a constant tail:

406

$$
F_{m}(\mathrm{t})=\left\{\begin{array}{rr}
\mathrm{F}_{m}^{0} \exp \left(-\left(t-t_{0}\right)^{2} / 2 c^{2}\right), & \mathrm{t}<t_{1} \\
\mathrm{~F}_{m}^{1}, & \mathrm{t} \geq t_{1}
\end{array}\right.
$$

407 where $\mathrm{F}_{m}^{0}$ is the maximum flux at time $t_{0}$ and $\mathrm{F}_{m}^{1}$ is the constant flux after time $t_{1}$ when $\mathrm{t}>t_{0}$

408 and $\mathrm{F}_{m}^{0} \exp \left(-\left(t_{1}-t_{0}\right)^{2} / 2 c^{2}\right)=\mathrm{F}_{m}^{1}, c$ controls the width in time of the Gaussian function.

$409 \quad \mathrm{~F}_{m}^{0} \exp \left(-\left(t-t_{0}\right)^{2} / 2 c^{2}\right)$ represents the crustal magma intrusion flux being generated by a

410 mantle plume head and $\mathrm{F}_{m}^{1}$ represents a plume tail induced magma flux. In our one-dimensional

411 treatment the flux has units of volume flux/area $([\mathrm{m} / \mathrm{s}])$.

412 Assuming a radius $\mathrm{R}$ of the circular disk-like sill intrusions, the volume flux of magma

413 intrusion is then easily calculated as $V_{m}(t)=F_{m}(\mathrm{t}) \pi R^{2} \cdot R$ is assumed to be 1000 times of the 
414 thickness of the sills emplaced during one modeled intrusion episode. Studies on concentrations

415 of $\mathrm{Ba}$ and $\mathrm{Nb}$ in picrites suggest a $0.1 \sim 2$ weight percent (wt $\%$ ) of $\mathrm{CO}_{2}$ concentration in the

416 original mantle derived magma ${ }^{52,53}$ and we here assume this concentration to be $1.5 \mathrm{wt} \%$ for the

417 multi-sill model and $1.2 \mathrm{wt} \%$ for the analytic model, with degassing efficiencies of $55 \%$ for

418 intrusion and $70 \%$ for extrusion ${ }^{10,54}$, depending on the timing of declaration of main phase of

419 flood basalt eruptions, the model results in a time series of $\mathrm{CO}_{2}$ outgassing flux (Fig. 4b). The 420 modeled $\mathrm{CO}_{2}$ outgassing flux is then used as an input into a multi-box long-term carbon cycle

421 and climatic response model described below.

422 The initial density structure of continental crust $\rho_{c}(z, t=0)$ is simplified according to ref.

$423{ }^{33}$ with a linear fit that increases from $2650 \mathrm{~kg} / \mathrm{m}^{3}$ at the surface to $3100 \mathrm{~kg} / \mathrm{m}^{3}$ at the Moho at

$424 L_{M}=40 \mathrm{~km}\left(\right.$ Fig. 2b). The crustal density structure $\rho_{c}(z, t)$ changes with intrusions of fluid

425 magma of $2800 \mathrm{~kg} / \mathrm{m}^{3}$ which increases to a depth dependent density $\rho_{s}(z)=2900+$

$426200 \times\left(\frac{z}{L_{M}}\right) \mathrm{kg} / \mathrm{m}^{3}$ for solidified basalt (Fig. 3).

427 LOSCAR climate model

428 We use the Long-term Ocean-Sediment CArbon Reservoir model (LOSCAR), v 2.0.4.3

42938,48 to simulate the global temperature response to the $\mathrm{CO}_{2}$ outgassing during LIP emplacement.

430 Our model setup and parameters follows that of refs. ${ }^{7,55}$ for the Deccan Traps case and ref ${ }^{46}$ for

431 the CRBG-MCO case. Specifically, we set $\left[\mathrm{Mg}^{2+}\right]=42$ (46 for CRBG-MCO) $\mathrm{mmol} / \mathrm{kg}$ and

$432\left[\mathrm{Ca}^{2+}\right]=21(14.8$ for CRBG-MCO) $\mathrm{mmol} / \mathrm{kg}$ as equilibrium constants for carbonate chemistry

433 calculations for K/Pg seawater. Sediment depth resolution was divided with the standard $500 \mathrm{~m}$

434 interval rather than the previously used more finely subdivided $100 \mathrm{~m}$ depth intervals because

435 both show similar results but the models with a finer resolution take more than twenty times

436 longer. The exponential constant $\left(n_{s i}\right)$ used in the silicate weathering feedback equation was 0.6 
437 (0.2 for CRBG-MCO) following refs. ${ }^{7,46,55}$. A pre-event baseline $p C O 2$ of 600 (280 for CRBG-

438 MCO) ppm was used after refs. ${ }^{7,55}$ by restarting the model with pre-calculated steady state model

439 parameters. The calculated global temperature response due to $\mathrm{CO}_{2}$ outgassing from the LIP

440 emplacement is presented in Fig. 4ef of the main text. Note that exact curve fitting of the global

441 temperature could be possible but is not the point of this study, rather, we here try to demonstrate

442 quantitatively with reasonable and well-studied controlling parameters that our coupled sill

443 intrusion and LOSCAR models are capable of predicting similar patterns of climate and LIP

444 behaviors when compared to the observations.

445 Analytic sill intrusion model

446 To demonstrate the plausibility of our conceptual model for significant intrusion before

447 continental flood basalt extrusion we first consider a simplified analytic version based on a

448 balance of thermal energy. The temperature structure of the crust above intruding sills is

449 assumed to reach steady state $(\partial T(z, t) / \partial t=0)$ immediately with the changes of magma supply

450 flux. This is purely for the sake of analytic simplification and induces inaccuracy in time for

451 temperature changes, which is treated more realistically in the multi-sill model described later.

452 For this approach the domain of interest is between the surface and the top of an intruding sill so

453 we neglect effects of downward crustal advection beneath the intruding sill $(v=0)$. Over this

454 domain, we only consider the liberation of heat $\left(H_{m} /\left(\rho(z) C_{p}\right)\right)$ from the sill as a bottom heat

455 flux boundary condition and temperature correlates linearly with depth. The thermal equation 1

456 is then simplified to:

$$
N u(z, t) \kappa \frac{\partial^{2} T}{\partial z^{2}}=0
$$

458 Integrating equation 3 with respect to depth $\mathrm{z}$ and assuming that at the bottom boundary the heat 459 flux $\left(Q_{\text {sill }}\right)$ is sourced from the cooled and solidified sill with a constant $N u$ yields: 


$$
N u \times k \frac{\partial T}{\partial z}=Q_{\text {sill }}
$$

461 Where $k=\kappa \rho_{f} C_{p}=3.3[\mathrm{~W} / \mathrm{mK}]$ is the constant thermal conductivity of crustal rocks. The heat 462 flux coming from the sill is taken to be:

$$
Q_{\text {sill }}=F_{m}(t) \times \rho_{f}\left(L+\left(T_{l}-T_{s}\right) C_{p}\right)
$$

464 where $\rho_{f}=2800\left[\mathrm{~kg} / \mathrm{m}^{3}\right]$ is the density of the fluid magma and $L=4 \times 10^{5}[\mathrm{~J} / \mathrm{kg}]$ is the 465 latent heat of solidification, $T_{s}=1000{ }^{\circ} \mathrm{C}$ is the magma solidus and $T_{l}=1200{ }^{\circ} \mathrm{C}$ is the magma 466 liquidus. Applying a top boundary condition of $T(0, t)=0{ }^{\circ} \mathrm{C}$ and a moving bottom boundary 467 condition of $T\left(Z_{\text {in }}, t\right)=T_{s}$ where $Z_{\text {in }}$ is the evolving sill intrusion depth, we have a thermal 468 gradient of $\partial T / \partial z=\left(T_{s}-T(0, t)\right) / Z_{\text {in }}$, which is plugged into equation 4 and 5 to determine 469 the intrusion depth as:

$$
Z_{\text {in }}=\frac{N u \times k \times T_{s}}{F_{m} \rho_{f}\left(L+\left(T_{l}-T_{s}\right) C_{p}\right)}
$$

471 For the example used here we assume the plume head is controlled by $F_{m}^{0}=$

$47215 \mathrm{~cm} / \mathrm{yr}, t_{0}=170 \mathrm{kyrs}$ and $c=210 \sqrt{2 / \pi}$ kyrs followed by a plume tail of constant $\mathrm{F}_{m}^{1}=$

$4736 \mathrm{~cm} / \mathrm{yr}$ thickening rate. Extended Data Fig. 1a shows this example flux-time curve and

474 Extended Data Fig. 1b shows the resulting variation of the intrusion depth given by equation 6.

475 This sill intrusion depth along with the density structure and an assumed critical overpressure for 476 initiation of eruptions $\Delta P_{c}=10 \mathrm{MPa}{ }^{13,56,57}$, determines whether magma can extrude subaerially

477 or is intruded within the crust. We also assume that deepening of sill intrusions is taken to imply 478 replacement of felsic continental crust with denser basaltic rocks. This densification of the crust 479 then affects the depth where magma in a sill can be erupted which is termed as 'level of 480 eruptibility' (see main text). For extrusion to occur there has to be enough pressure in the magma 481 sill to drive the magma to the surface. We assume that the pressure in the magma sill is just the 
overburden pressure:

483

$$
P_{O B}\left(Z_{i n}, t\right)=\int_{0}^{Z_{\text {in }}} \rho_{c}(z, t) g d z
$$

484 where $\rho_{c}(z, t)$ is the crustal density profile. We determine the magma eruptibility by whether the 485 magma pressure head $P_{h}(z, t)$ at the surface $(z=0)$ is larger than $\Delta P_{c}$ when sourced from the 486 intruding sill at depth $Z_{\text {in }}$, where

$$
P_{h}(0, t)=P_{O B}\left(Z_{i n}, t\right)-\rho_{f} g Z_{\text {in }}
$$

488 and this is equivalent to whether the overburden of the intruding sill is on average denser than 489 fluid magma to an extent that:

$$
\bar{\rho}_{o b}>\rho_{f}+\Delta P_{c} / g Z_{i n}
$$

491 Where $\bar{\rho}_{o b}$ is the average overburden density.

492 Flood basalt eruptions then could happen in two ways. If the initial sills are deeper than 493 the level of eruptibility then the condition is met so extrusion could occur. This might only 494 happen when the initial magma flux is low and the intrusion is deep. Alternatively, a sill can 495 move up to a depth much shallower than the level of eruptibility and then move downward as 496 mafic magma in the sill cools and crystallizes. The sill intrusion moves downward as the flux of 497 magma wanes and so the heat released by the magma decreases (as indicated in Extended Data 498 Fig. 1b). We assume that as the sill moves down it leaves behind intrusions with the density of 499 solid basalt $\left(\rho_{s}(z)\right)$. Now the overburden will be a mix of initial low-density felsic crust and 500 higher density solidified basalt. For a linear increase of initial crustal density with depth (Fig. 2a) 501 eruption can happen if:

$$
Z_{\text {in }} \geq \frac{\left[\rho_{s}\left(Z_{\text {inm }}\right)+\rho_{s}\left(Z_{i n}\right)-\rho_{c}(0)-\rho_{c}\left(Z_{i n m}\right)\right] \times Z_{i n m}+2 \Delta P_{c} / g}{\rho_{s}\left(Z_{i n m}\right)+\rho_{s}\left(Z_{i n}\right)-2 \rho_{f}}
$$


503 where $Z_{i n m}=\frac{N u \times k \times T_{S}}{\mathrm{~F}_{m}^{0} \rho_{f}\left(L+\left(T_{l}-T_{s}\right) C_{p}\right)}$ is the minimum depth of the sill intrusions. When this

504 condition is met the magma pressure head at the surface is greater than $\Delta P_{c}$, the critical pressure

505 for initiating an eruption. Extended Data Fig. 1c shows how magma pressure head varies in time.

506 Once the timing of the onset of eruptions is determined, the model predicts a $\mathrm{CO}_{2}$ degassing flux

507 given the assumed magma concentration and degassing efficiencies. Using the $\mathrm{CO}_{2}$ degassing

508 flux as an input for the LOSCAR model we can calculate the global averaged atmospheric $\mathrm{CO}_{2}$

509 concentration (Extended Data Fig. 1d) and temperature changes (Extended Data Fig. 1e) with

510 time relative to the $\mathrm{K} / \mathrm{Pg}$ boundary.

\section{Multi-sill intrusion model}

512 Our multi-sill intrusion model builds upon previous numerical studies on the genesis and

513 evolution of evolved crustal magmas ${ }^{37,49}$. By accounting for heat transfer and mass advection

514 during repetitive sill intrusions, such models can quantify changes in melt fraction and chemical

515 compositions of the mantle plume induced magma that intrudes into the crust and mixes with

516 crustal melts. As we are concerned with magma eruptibility rather than the chemical evolution of

517 the system, our approach neglects chemical reactions of the magma and country rock. We focus

518 on how changes in crustal temperature and composition structures control the depth of sill

519 intrusions and the density structure of the crust.

520 We argue in the main text that the depth of sill intrusion is important for determining

521 whether magma is emplaced as intrusions or eruptions. Some studies assume an initial intrusion

522 depth and that subsequent sills are emplaced over, under or within the earlier sills ${ }^{37,49}$. Other

523 studies treat sill intrusion depths through time as stochastic processes ${ }^{58,59}$. As noted below, there

524 is considerable evidence that the thermal structure of the crust has a large influence on the depth

525 of sill intrusion. It is also clear that sill intrusion alters the crustal temperature structure and so 
526 can lead to an evolution of sill intrusion depths. Because crustal thermal structure does not

527 respond instantaneously to changes in magmatic heat input, we derive a time dependent model

528 that includes diffusion and advection of heat as described by equation 1 . Before describing that

529 model, we briefly review some recent studies of sill intrusion.

530 One of the most discussed ideas about sill opening depth is that magmatic sills form at

531 the 'level of neutral buoyancy' (LNB) ${ }^{60}$. This model assumes that crustal density increases with

532 depth and that magma pools at the LNB where the country rock density equals the magma

533 density. This works in analog laboratory models only if the 'crustal' material has negligible

534 strength. However, many observations are at odds with the LNB concept (see ${ }^{61,62}$ and references

535 therein). For example, this idea was tested by Hooft and Detrick ${ }^{31}$ at mid-ocean ridges where

536 seismic observations are of sufficient quality to determine the density structure above the magma

537 filled sills. They showed that the sills were located deeper than the LNB and they suggested that

538 the strength of cold crust may be important. Some other studies imaged sill intrusions within

539 lower density sedimentary basins which situate shallower than the LNB (e.g. ${ }^{63}$ and references

540 therein).

541 Some previous workers focus on the effects of mechanical strength changes across layers

542 which deflect a dike into sills and hence the sill intrusion depth is determined by the location of

543 the layer boundary ${ }^{61,64}$. A recent analogue model study summarizes that buoyancy pressure from

544 density contrast between host rock and the injecting fluid, rigidity contrast and lateral

545 compression are the major controls on formation of sills ${ }^{65}$. Menand ${ }^{61}$ reviewed existing models

546 for sill emplacement depths as controlled by four major factors: (1) the buoyancy pressure due to

547 the density contrast between host rock and injecting fluid, (2) the rigidity contrast between strata,

548 (3) the rheology control between warm ductile material and cold brittle material, and (4) rotation 
549 of deviatoric stress. These four factors can be further grouped into two major effects: either from

550 buoyancy driving pressure controlled by density structures or effective resistant strength

551 structure controlled by rigidity, rheology or stress state. All these factors are functions of

552 temperature which makes sill intrusion depth strongly dependent on thermal structures.

553 Morgan and Chen ${ }^{66}$ were the first to suggest that temperature was critical in controlling the

554 depth of magma lenses at mid-ocean ridges. A recent three-dimensional numerical modeling 555 study of magma intrusion into the continental crust indicates that rheology and temperature of

556 the host rocks are the key controls of how magma is emplaced ${ }^{67}$. Parsons et al. ${ }^{68}$ first suggested

557 that at large rheology contrasts where lower viscosity ductile layers are adjacent to a higher

558 viscosity elastic layer, the least principal stress can be rotated vertically due to horizontal dike

559 opening. This rotation of the least principal stress can arrest upward dike propagation and induce

560 lateral sill intrusions. Similar behavior of dike arrest is described by ${ }^{69}$ for rifts where lithosphere-

561 cutting dikes stop when the 'driving pressure' (magma pressure minus lithospheric stress normal

562 to the dike wall) is too small. This idea has also been used to explain analogue model results

563 showing that horizontal compressive stress can modify the path of fluid crack from vertical to

564 horizontal ${ }^{70}$.

565 Here, we assume that sill intrusion depth evolves with the thermo-mechanical state and

566 density structure following previous studies of effects of thermal and stress states on sill

567 formations ${ }^{66,68}$. For a column of magma rising through crust with density that increases with

568 depth, the magma overpressure (magma pressure minus lithostatic pressure defined here as

569 driving pressure $P_{d}$ ) will be greatest at the level of neutral buoyancy. However, if the rocks are

570 cold and strong at this depth the magma should not be able to force a sill to open. We estimate

571 the resistance to sill opening as resistance pressure $\left(P_{r}\right) . P_{r}$ depends partly on the host rock 
572 temperature in that it controls whether magma will freeze before the sill intrusions can be open.

$573 P_{r}$ depends also on the composition and temperature controlling horizontal stress $\left(\sigma_{h}(z, t)\right)$

574 which acts normal to the vertical dike opening wall, because it controls where a vertical sill

575 feeding dike is stopped due to smaller driving pressure relative to that of the horizontal

576 compressive stress. We assume that a sill opens where the breakout pressure $\left(P_{B K}=P_{d}-P_{r}\right)$,

577 namely the difference between the driving pressure $P_{d}$ and the resistance pressure $P_{r}$ is the

578 largest as the maximum breakout pressure $\left(P_{B K}\left(Z_{i n}\right)=P_{B K m}\right)$ (Extended Data Fig. 2).

579 The driving pressure for sill intrusion is computed by integrating density difference

580 between the fluid magma $\rho_{f}$ and the country rock $\rho_{c}$ along a vertical melt migration conduit

581 upward from the Moho level reservoir:

$$
P_{d}(z)=\int_{Z_{\text {moho }}}^{z}\left(\rho_{c}-\rho_{f}\right) g d z
$$

583 This neglects any viscous pressure changes due to flow of the low viscosity primitive magma.

584 For the driving pressure $P_{d}$, although the density difference between fluid magma and mantle

585 country rock can be large, we assume the magma generated from the mantle plume gains

586 negligible pressure head as it percolates through the low permeability melt channels in the upper

587 mantle. Magma is assumed to then accumulate in the Moho-level magma reservoirs similar to

588 that of previous studies of continental intrusions ${ }^{28,29,62}$.

The resistance pressure $P_{r}$ comes from two parts, namely, the thermal arrest pressure $P_{T A}$

590 and the remained (un-relaxed) dike opening induced horizontal compressive stress $\sigma_{h} . P_{T A}$ is the

591 required magma pressure for sustaining a thin but laterally wide sill intrusion. We estimate this

592 pressure following previous 'thermal entry' length calculations ${ }^{71,72}$, which consider the pressure

593 needed to drive magma to flow a long distance before freezing. Here, we assume a sill of 
594 thickness $w=1$ meter and a flow distance $R_{f z}=200 \mathrm{~km}$ before the magma fully freezes. The 595 magma propagation in such a sill is assumed to be simplified as a thin channel flow with an 596 average velocity of:

$$
\bar{u}=\frac{w^{2}}{12 \eta_{m}} \frac{d P}{d x}
$$

where pressure gradient $d P / d x=P_{T A} / R_{f z}$, assuming stable source pressure of $P_{T A}{ }^{73}$ and $\eta_{m}=$ $599100 \mathrm{~Pa} \cdot \mathrm{s}$ is the assumed viscosity for fluid magma following ${ }^{74}$. Then the thermal arrest

600 pressure $P_{T A}$ to drive a high aspect ratio thin channel sill intrusion before it freezes is:

$$
P_{T A}=\frac{192 \times \kappa \times \eta_{m} \times R_{f z}{ }^{2} \times \lambda^{2}}{w^{4}}
$$

602 where $\kappa$ is the thermal diffusivity. The freezing distance $R_{f z}=\bar{u} t_{f z}$ is calculated assuming a 603 freezing time $t_{f z}=w^{2} /\left(16 \kappa \lambda^{2}\right)$, which is the approximate time for a thin channel fluid magma 604 flow with thickness of $w$ to freeze and $\lambda$ is a dimensionless parameter determined by temperature 605 of the country rock at the sill intrusion depth $T\left(Z_{i n}\right)^{72,75}$ and is expressed in an implicit function 606 only solved numerically:

$$
\lambda=\frac{\exp \left(-\lambda^{2}\right)}{\pi^{\frac{1}{2}} S}\left[\frac{\theta}{\operatorname{erfc}(-\lambda)}-\frac{1-\theta}{\operatorname{erfc}(\lambda)}\right]
$$

608 Where dimensionless solidus temperature $\theta=\left[T_{s}-T\left(Z_{\text {in }}\right)\right] /\left[T_{l}-T\left(Z_{\text {in }}\right)\right]$, and the Stefan 609 number $S=L /\left[C_{p}\left(T_{l}-T\left(Z_{\text {in }}\right)\right)\right]$, where $T_{s}$ is the solidus temperature and $T_{l}$ is the liquidus 610 temperature, here taken to be the intrusion temperature. A vertical dike is assumed to propagate quasi-periodically upward to feed sill intrusions

612 from the magma reservoir at the base of the crust. As the dike opens it induces an instant elastic 613 increase in the lateral compressive stress. If the dike freezes in cold and strong crust that 614 behaves mainly elastically, the compressive stress increase can remain for a long period of time 
615 and this should inhibit vertical propagations of later dikes. If the dike intrudes and freezes in

616 hotter and lower viscosity crust, the initial increase in lateral compressive stress can be

617 effectively relaxed between dike events. Following the model of Parsons et al., ${ }^{68}$ that a sill can

618 form at brittle-ductile transitions, we calculate the second part of the model resistant pressure as

619 the temporally variable horizontal stress $\sigma_{h}(z, t)$ induced by a dike opening. Assuming the crust

620 behaves as a Maxwell viscoelastic material ${ }^{73}$ with laboratory constrained properties ${ }^{76,77}$ we can

621 estimate the amount of stress relaxation between intrusion events as functions of temperature and

622 assumed composition. When a dike propagates vertically and opens laterally with pressure

623 distribution of magma driving pressure $P_{d}(z)$, it induces a compressive horizontal stress

$624 \sigma_{h}(z, t=0)=P_{d}(z)$, which relaxes quickly at low viscosity regions. During the quasi-periodic

625 intersessions of $\Delta t$ (on the order of a few thousand years depending on the magma flux) between

626 intrusions, this initial dike induced horizontal compressive stress $\sigma_{h}(z, t=0)$ relaxed to

$627 \sigma_{h}(z, t=\Delta t)$ following a Maxwell relaxation stress relation ${ }^{73}$ :

628

$$
\sigma_{h}(z, t=\Delta t)=\sigma_{h}(z, t=0) \exp \left(-\frac{E \Delta t}{2 \mu}\right)
$$

629 where the assumed Young's modulus $E=30 \mathrm{GPa}^{51}$, and the strain rate independent viscosity of 630 the country rock $\mu$ is calculated according to ${ }^{50}$ with the power $n=1$ :

$$
\mu=(3 A)^{-1} \times \exp \left(\frac{Q}{n R T\left(Z_{\text {in }}\right)}\right)
$$

632 where $\mathrm{A}$ is an empirical lab-determined viscosity pre-factor, $\mathrm{Q}$ is the activation energy, $\mathrm{R}=$

$6338.314[\mathrm{~J} /(\mathrm{mol} \cdot \mathrm{K})]$ is the gas constant. For upper crust, we use lab constrained equivalent

634 Newtonian flow rule with $\mathrm{A}=0.0052\left[\mathrm{MPa}^{-1} \mathrm{~S}^{-1}\right]\left(\right.$ calculated from $\left.2 / 3 \times 1.57 \times(1 \mathrm{e}-3) \times 50^{0.41}\right)$

635 and $\mathrm{Q}=131500[\mathrm{~J} / \mathrm{mol}]^{76}$. For the lower crust, for simplicity, $\mathrm{A}$ is scaled from the upper crust

636 value to be 5 orders of magnitude smaller and hence the resulting viscosity is 5 orders of 
637 magnitude higher given the same temperature. For the $2 \mathrm{~km}$ of upper mantle, we apply lab-

638 constrained Newtonian rheology from ref. ${ }^{77}$ where the equivalent $\mathrm{A}=0.000 \dot{6}\left[\mathrm{MPa}^{-1} \mathrm{~S}^{-1}\right]$

639 (calculated from $\left.2 / 3 \times 1 \mathrm{e} 6 \times(1 \mathrm{e} 4)^{-3} \times 1000\right)$ and $\mathrm{Q}=339000[\mathrm{~J} / \mathrm{mol}]$. For solidified magma,

640 we assume its A value to be 5 orders of magnitude larger and hence the resulting viscosity is 5

641 orders of magnitude lower than the mantle given the same temperature. To prevent numerical

642 localizations of sill intrusion at a specific grid, $T\left(Z_{\text {in }}\right)$ is approximated with an average

643 temperature of the country rocks near $Z_{\text {in }}$ within a thermal diffusion length during one numerical

644 time step of 1 Kyrs.

645 The initial vertical crustal temperature profile is taken to be piece-wise linear with the

646 initial upper crustal thermal gradient $d T / d Z(0 \sim 20 \mathrm{~km})=40[\mathrm{~K} / \mathrm{km}](45[\mathrm{~K} / \mathrm{km}]$ for CRBG-

647 MCO case) and lower crustal thermal gradient $d T / d Z(20 \sim 40 \mathrm{~km})=15[\mathrm{~K} / \mathrm{km}](\mathrm{Fig}$. 3). The

648 magma supply flux (Fig. 4a) is assumed with $F_{m}^{0}=15[\mathrm{~cm} / \mathrm{yr}](10[\mathrm{~cm} / \mathrm{yr}]$ for CRBG -

649 MCO case), $t_{0}=170[\mathrm{kyrs}]$ and $c=90 \sqrt{2 / \pi}[\mathrm{kyrs}], F_{m}^{1}=3[\mathrm{~cm} / y r]$.

650 Numerically, the heat equation 1 is discretized into a one-dimensional array of grids, and

651 is solved by forward finite difference methods. We apply a semi-Lagrangian Crank-Nicolson

652 algorithm ${ }^{78}$, which is coupled with one-half backward implicit step ${ }^{79}$ to damp the Crank-

653 Nicolson error oscillations introduced by sharp temperature corners from sill intrusions. As noted

654 above, the average effect of hydrothermal circulation is simulated by increasing the thermal

655 diffusivity $\kappa$ by a factor of $N u$. The efficiency of hydrothermal circulation should scale with

656 crustal permeability and thermal gradient. Hence it should depend on the existence of

657 interconnected cracks as well as the crustal thermal condition. Upper crustal thermal gradient and

658 fracture events should peak around the time when the magma flux $F_{m}(t)$ maximizes at $t_{0}$. Hence, 659 we assume $N u=25$ from the surface to $20 \mathrm{~km}$ when $t \geq t_{0}$ and $N u=1$ otherwise $(\mathrm{Nu}=$ 
30 for CRBG-MCO case). Note that measurements from Yellowstone indicate up to $2000 \mathrm{mWm}^{-}$

$6612^{2}$ of surface heat flux ${ }^{25}$, which is nearly 30 times of that of normal continental crust of $65 \mathrm{mWm}^{-2}$ 66273.

663 We determine the magma eruptibility by whether the magma pressure head at the surface $664\left(P_{h}(0)=\int_{Z_{\text {in }}}^{0}\left(\rho_{c}-\rho_{f}\right) g d z\right)$ is larger than the critical pressure $\left(\Delta P_{c}\right)$ for initiating an eruption 665 when sourced from the intruding sill at depth $Z_{\text {in }}$ :

$$
P_{h}(0)>\Delta P_{c}
$$

667 This is equivalent to considering whether the average density of the overburden of an intruding 668 sill is larger than the density of fluid magma to an extent of equation 9. During the initial phases 669 when the sill is deep or when the crust densifies due to sill intrusions, magma driving pressure at 670 the surface $P_{d}(0)$ can be positive, which means magma from the Moho reservoir has the 671 potential to erupt. However, we do not count major phase of flood basalts eruptibility when

672 magma is sourced from the Moho reservoir during the early phase of an LIP emplacement

673 because the pressure head should be consumed by lateral sill intrusions into the initial weaker 674 and lower density crust before magma can reach the surface. We do not consider viscous 675 resistances for sill or dike intrusions as they are negligible compared to the thermal arrest 676 resistance from sill intrusions ${ }^{74}$. We also neglect temporal variations in elastic overpressure from 677 the magma reservoir which can be responsible for finer time scale hiatuses in magma eruptions $678 \quad 28,29$.

679 We also include in the supplementary information with eight videos of the multi-sill 680 intrusion models (Video 1 to 4 for the Deccan case and Video 5 to 8 for the CRB case), which 681 illustrate in detailed the changes in crustal density, temperature, pressures, viscosity and sill 682 intrusion depths due to repetitive sill intrusions. Video 1 and 5 show the crustal densification 
683 process for comparison to the data in Fig. 2F. Video 2 and 6 present the crustal temperature and

684 pressures evolution. Note that for the assumed rheology parameters the thermal arrest resistance

685 pressure has the dominant effect on controlling sill intrusion depths when the sills are moving

686 upwards into weak lower part of the upper crust, but the dike related stress change becomes

687 important during the sill-deepening phase (starting $~ 175 \mathrm{kyr}$ for video 2 ) as the sills open into

688 stronger mafic intrusives. Video 3 and 7 show the variations in temperature and viscosity

689 structure resulted from the assumed lab-constrained rheological parameters. Video 4 and 8

690 include changes in sill intrusion depth, temperature, magma overpressure, magma breakout

691 pressure and magma overpressure if sourced from the intruding sill. With our model formulation,

692 the intruding depth is determined by considering both the density structure and the thermo-

693 mechanical conditions and hence is not always at the level of neutral buoyancy.

694

695 Data availability: For Fig. 1, global temperature change data are from ref. ${ }^{7}$ (DOI:

696 10.1126/science.aay5055) and Deccan Trap extrusive flux data are converted from ref. ${ }^{4}$ (DOI:

697 10.1126/science.aav1446). For Fig. 2, Seismic velocity data are converted from refs. ${ }^{19,33}$.

698 Code availability: All codes for our numerical calculations are available from X.T. upon request. 
700 48. Zeebe, R. E. LOSCAR: Long-term Ocean-atmosphere-Sediment CArbon cycle Reservoir 701 Model v2.0.4. Geosci. Model Dev. 5, 149-166 (2012).

702 49. Solano, J. M. S., Jackson, M. D., Sparks, R. S. J., Blundy, J. D. \& Annen, C. Melt Segregation in Deep Crustal Hot Zones: a Mechanism for Chemical Differentiation, Crustal Assimilation and the Formation of Evolved Magmas. J. Petrol. 53, 1999-2026

705 (2012).

706

707

50. Chen, Y. \& Morgan, W. J. A nonlinear rheology model for mid-ocean ridge axis topography. J. Geophys. Res. 95, 17583 (1990).

708

51. Behn, M. D. \& Ito, G. Magmatic and tectonic extension at mid-ocean ridges: 1. Controls 709 on fault characteristics. Geochemistry, Geophys. Geosystems 9, n/a-n/a (2008).

52. Kent, A. J. R. et al. Mantle heterogeneity during the formation of the North Atlantic Igneous Province: Constraints from trace element and Sr-Nd-Os-O isotope systematics of Baffin Island picrites. Geochemistry, Geophys. Geosystems 5, n/a-n/a (2004).

713 53. Sobolev, A. V., Krivolutskaya, N. A. \& Kuzmin, D. V. Petrology of the parental melts and 714 mantle sources of Siberian trap magmatism. Petrology 17, 253-286 (2009).

715 54. Hartley, M. E., Maclennan, J., Edmonds, M. \& Thordarson, T. Reconstructing the deep 716 CO2 degassing behaviour of large basaltic fissure eruptions. Earth Planet. Sci. Lett. 393,

718 55. Henehan, M. J., Hull, P. M., Penman, D. E., Rae, J. W. B. \& Schmidt, D. N. Biogeochemical significance of pelagic ecosystem function: an end-Cretaceous case study. $720 \quad$ Philos. Trans. R. Soc. B Biol. Sci. 371, 20150510 (2016).

721 56. Rubin, A. M. Getting granite dikes out of the source region. J. Geophys. Res. Solid Earth 
100, 5911-5929 (1995).

723 57. Jellinek, A. M. \& DePaolo, D. J. A model for the origin of large silicic magma chambers:

724 Precursors of caldera-forming eruptions. Bull. Volcanol. 65, 363-381 (2003).

725 58. Karakas, O., Degruyter, W., Bachmann, O. \& Dufek, J. Lifetime and size of shallow

727 59. Dufek, J. \& Bergantz, G. W. Lower Crustal Magma Genesis and Preservation: a Stochastic Framework for the Evaluation of Basalt-Crust Interaction. J. Petrol. 46, 2167-

730

60. Ryan, M. P. Neutral buoyancy and the mechanical evolution of magmatic system. Magmat. Process Physicochem. Princ. 259-287 (1987).

732 61. Menand, T. Physical controls and depth of emplacement of igneous bodies: A review. Tectonophysics 500, 11-19 (2011).

734 62. Rohrman, M. Intrusive large igneous provinces below sedimentary basins: An example 735 from the Exmouth Plateau (NW Australia). J. Geophys. Res. Solid Earth 118, 4477-4487 (2013).

737 63. Magee, C. et al. Lateral magma flow in mafic sill complexes. Geosphere 12, 809-841 (2016).

739 64. Menand, T. The mechanics and dynamics of sills in layered elastic rocks and their implications for the growth of laccoliths and other igneous complexes. Earth Planet. Sci.

742 65. Sili, G., Urbani, S. \& Acocella, V. What Controls Sill Formation: An Overview From 743 Analogue Models. J. Geophys. Res. Solid Earth 124, 8205-8222 (2019).

744 66. Morgan, J. P. \& Chen, Y. J. The genesis of oceanic crust: Magma injection, hydrothermal 
circulation, and crustal flow. J. Geophys. Res. 98, 6283 (1993).

746 67. Gorczyk, W. \& Vogt, K. Intrusion of Magmatic Bodies Into the Continental Crust: 3-D

$747 \quad$ Numerical Models. Tectonics 37, 705-723 (2018).

748 68. Parsons, T., Sleep, N. H. \& Thompson, G. A. Host rock rheology controls on the 749 emplacement of tabular intrusions: Implications for underplating of extending crust.

$750 \quad$ Tectonics 11, 1348-1356 (1992).

751 69. Buck, W. R. The role of magma in the development of the Afro-Arabian Rift System. 752 Geol. Soc. London, Spec. Publ. 259, 43-54 (2006).

753 70. Menand, T., Daniels, K. A. \& Benghiat, P. Dyke propagation and sill formation in a 754 compressive tectonic environment. J. Geophys. Res. 115, B08201 (2010).

755 71. Spence, D. A. \& Turcotte, D. L. Magma-driven propagation of cracks. J. Geophys. Res. $756 \quad$ Solid Earth 90, 575-580 (1985).

757 72. Fialko, Y. A. \& Rubin, A. M. Thermodynamics of lateral dike propagation: Implications 758 for crustal accretion at slow spreading mid-ocean ridges. J. Geophys. Res. Solid Earth 103, $759 \quad 2501-2514(1998)$.

760 73. Turcotte, D. L. \& Schubert, G. Geodynamics. (Cambridge University Press, 2002). doi:10.1017/CBO9780511807442

762 74. Lister, J. R. \& Kerr, R. C. Fluid-mechanical models of crack propagation and their 763 application to magma transport in dykes. J. Geophys. Res. 96, 10049 (1991).

764 75. Carslaw, H. S. \& Jaeger, J. C. Conduction of Heat in Solids. (Oxford University Press, 765 1959).

766 76. Wang, J. N., Hobbs, B. E., Ord, A., Shimamoto, T. \& Toriumi, M. Newtonian Dislocation 767 Creep in Quartzites: Implications for the Rheology of the Lower Crust. Science (80-. ). 

265, 1204-1206 (1994).

769 77. Hirth, G. \& Kohlstedt, D. Rheology of the upper mantle and the mantle wedge: A view from the experimentalists. Geophys. Monogr. Ser. 138, 83-105 (2003).

771 78. Spiegelman, M. \& Katz, R. F. A semi-Lagrangian Crank-Nicolson algorithm for the numerical solution of advection-diffusion problems. Geochemistry, Geophys. Geosystems

$7737,(2006)$.

774 79. Britz, D., Østerby, O. \& Strutwolf, J. Damping of Crank-Nicolson error oscillations. $775 \quad$ Comput. Biol. Chem. 27, 253-263 (2003).

776 80. Schoene, B. et al. An evaluation of Deccan Traps eruption rates using geochronologic data. Geochronol.Discuss. (2020). doi:https://doi.org/10.5194/gchron-2020-11

778 81. D'Hondt, S. \& Lindinger, M. A stable isotopic record of the Maastrichtian ocean-climate 779 system: South Atlantic DSDP site 528. Palaeogeogr. Palaeoclimatol. Palaeoecol. 112, 363-378 (1994).

781 Acknowledgments: This work greatly benefited from discussions with Eunseo Choi, Jean782 Arthur Olive, William Ryan, Elizabeth Fischer and Courtney Sprain. We thank reviewers 783 Jennifer Kasbohm, Jon Blundy, Mark Richards and Tushar Mittal for their meticulous and 784 constructive reviews. We also thank Richard Zeebe for sharing the LOSCAR code. This work is 785 supported by NSF grants OCE-1654745.

786 Author contributions: X.T., advised by W.R.B., conducted the model experiments and both 787 authors wrote the manuscript.

788 Competing interests: Authors declare no competing interests.

789 Additional information

790 Supplementary information of four videos is available for this paper. 
791 Correspondence and requests for materials should be addressed to X. T. at email address:

792 xtian@1deo.columbia.edu.

$\mathbf{a}$
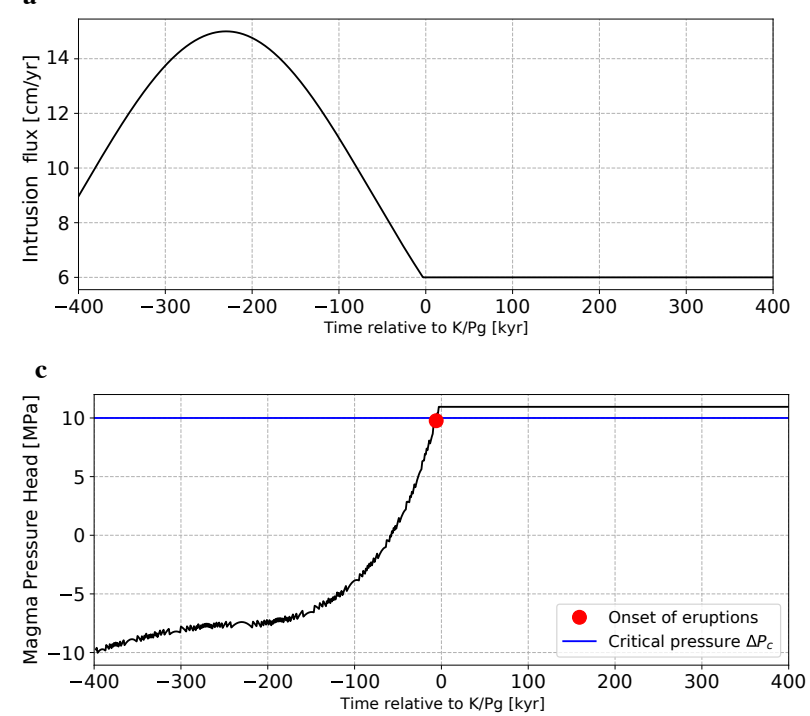

$\mathbf{e}$

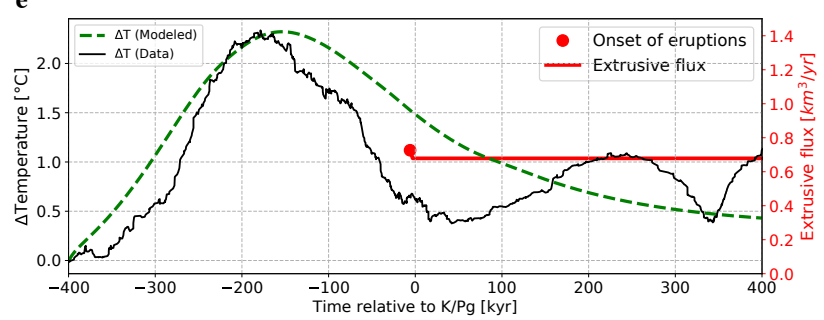

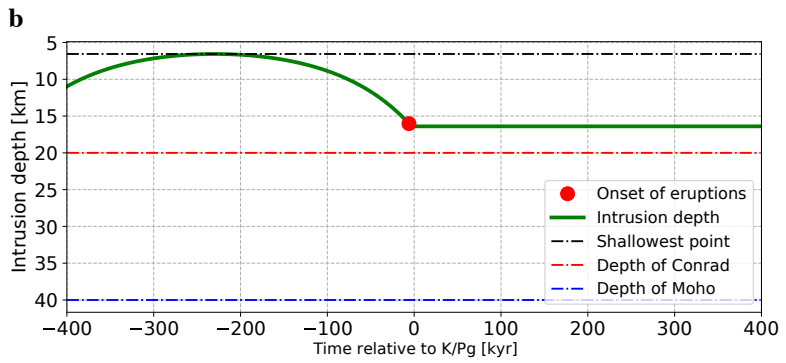

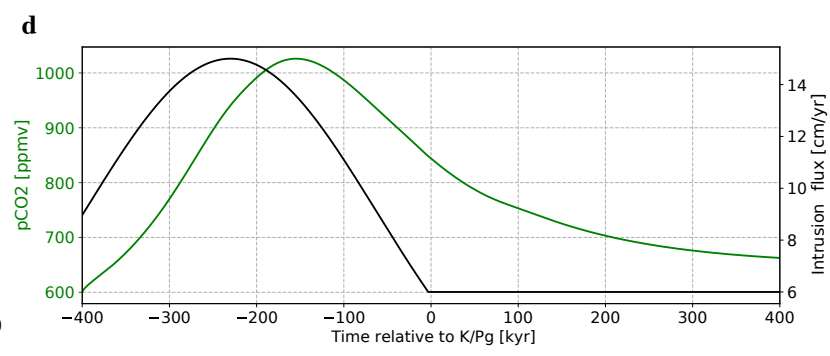

793

794

Extended Data Fig. 1 I Example of the steady-state analytic model results as functions of time relative to the

795 Cretaceous-Paleogene (K/Pg) boundary. a, Assumed Gaussian sill opening flux in terms of magma volume flux

796 per unit area of the sill. b, Sill intrusion depth for the melt flux of (a) and the thermal energy balance of equation (6).

797 c, Magma pressure head at the surface sourced from the intruding sill. Magma eruption is possible when this

798 pressure equals to the critical pressure $\Delta P_{c}$ at around $\mathrm{K} / \mathrm{Pg}$. For this case, magma flux from $-400 \mathrm{kyrs}$ to 0 kyrs is

799 intruded. d, global averaged atmospheric $\mathrm{CO}_{2}$ concentration with time predicted by the LOSCAR climate model. e,

800 global temperature change predicted by the LOSCAR model along with the extrusive flux with time to compare with

801 the observation in Fig. 1a. 


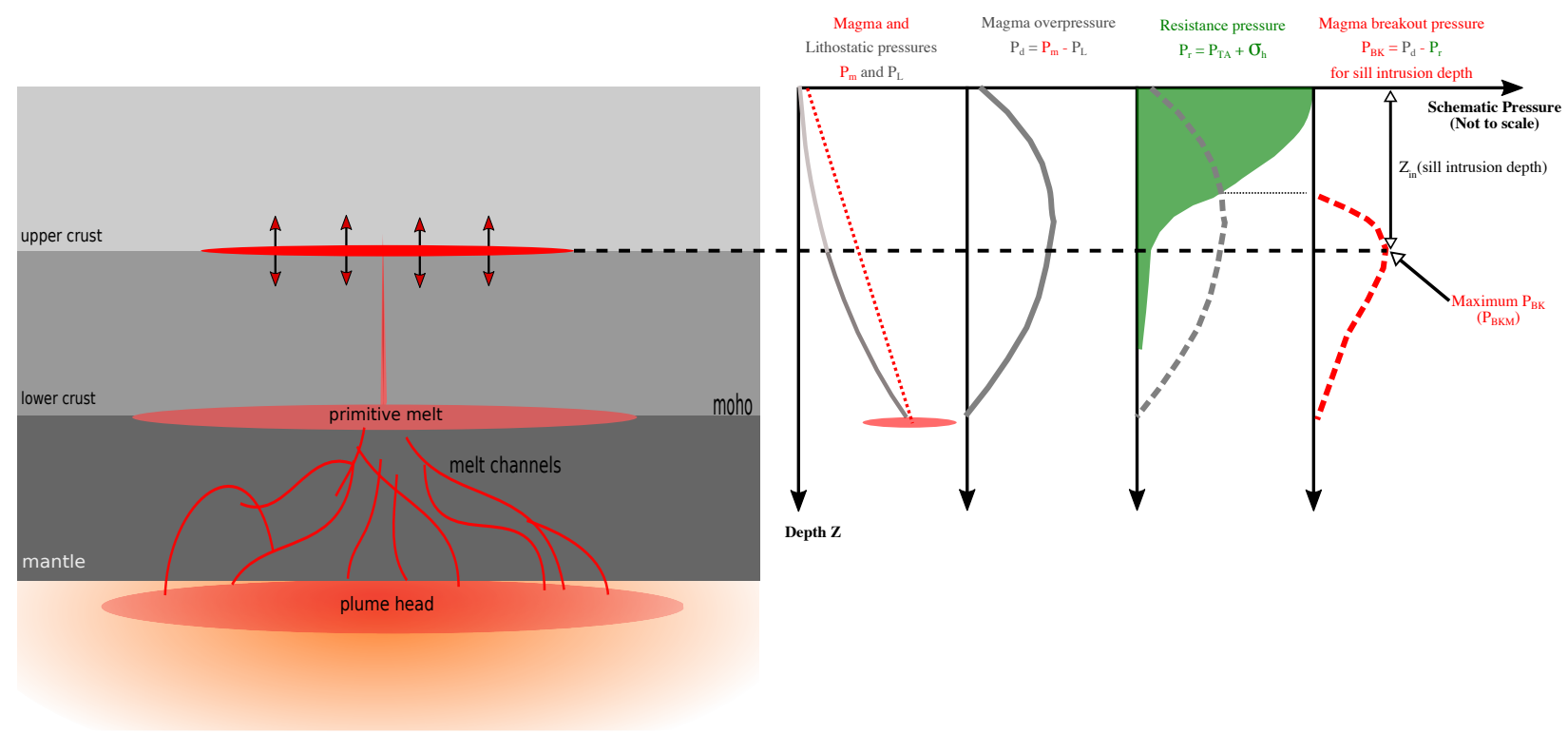

803 Extended Data Fig. 2 I Schematic illustrations of how to determine the depth for a sill intrusion at maximum

804 breakout pressure. Magma overpressure $\left(\mathbf{P}_{\mathrm{d}}\right)$, resistance pressure $\left(\mathbf{P}_{\mathrm{r}}\right)$ and magma breakout pressure $\left(\mathbf{P}_{\mathrm{BK}}\right)$

805 for determining sill intrusion depth $\left(Z_{\text {in }}\right)$.

807 Supplementary Information Video 1 and 5 | Video for modeled changes in crustal density due to evolving sill

808 intrusions. Model time is shown at the upper left. Green line shows the extent and value of the averaged overburden 809 density. Purple line shows the evolving crustal densities due to sill intrusions. The red dot indicates the sill intrusion 810 depth and the magma density. The dashed grey line shows the initial crustal density profile. 


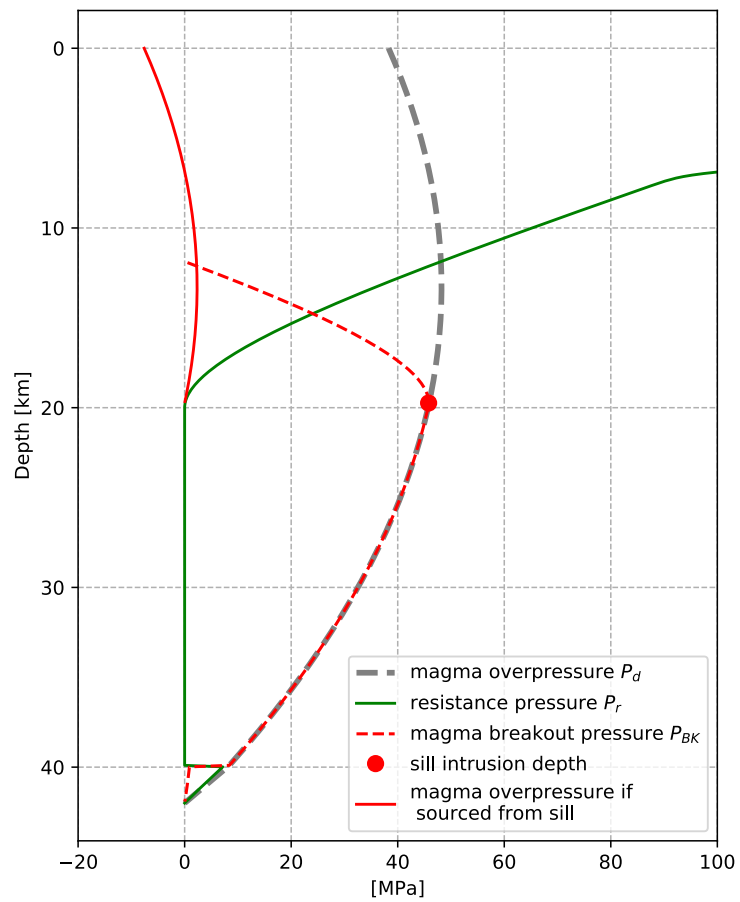

813 Supplementary Information Video 2 and 6 | Video for modeled changes in temperature and pressures due to

814 evolving sill intrusions. Model time is shown at the upper left. Left panel: temperature changes due to sill intrusions.

815 The blue and red dashed lines indicate magma solidus and liquidus respectively. Right panel: changes in pressures

816 due to sill intrusions (initial condition and legends are shown as the figure above: the dashed grey line is for the

817 magma overpressure (driving pressure $\mathrm{P}_{\mathrm{d}}$ ). The green line is for the resistance pressure $\mathrm{P}_{\mathrm{r}}$. The dashed red line is for

818 the magma breakout pressure $\mathrm{P}_{\mathrm{BK}}$. The solid red line is for the magma overpressure if sourced from the intruding sill.

819 Red dots indicate depth of sill intrusions).

820 Supplementary Information Video 3 and 7 | Video for modeled changes in temperature and viscosity due to

821 evolving sill intrusions. Model time is shown at the upper left. Left panel: temperature changes due to sill intrusions.

822 The blue and red dashed lines indicate magma solidus and liquidus respectively. Right panel: the dashed grey line is

823 for the initial viscosity. The solid line is for the evolving viscosity structure. Red dots indicate depth of sill intrusions.

824 Supplementary Information Video 4 and 8 I Video for modeled changes in sill depths, temperature and

825 magma pressures due to evolving sill intrusions. Model time is shown at the lower left. Top panel: sill intrusion

826 depth given the melt flux with time. Lower left panel: temperature changes due to sill intrusions. The blue and red

827 dashed lines indicate magma solidus and liquidus respectively. Lower right panel: the dashed grey line is for the 
828 magma overpressure (driving pressure $\mathrm{P}_{\mathrm{d}}$ ). The dashed red line is for the magma breakout pressure $\mathrm{P}_{\text {ВК. The solid }}$

829 red line is for the magma overpressure if sourced from the intruding sill. Red dots indicate depth of sill intrusions. 


\section{Discussion on differences in geochronology age models for Deccan Traps}

831

Two very different approached to estimating the ages of the basalts of the Deccan traps

833 have been reported in recent years and thy give somewhat different estimates of those ages. Age

834 model 1 (M1) from Schoene et al., $(2019)^{5}$ used U-Pb geochronology by isotope dilution-

835 thermal ionization mass spectrometry, which provides analytical uncertainties $( \pm 2 \sigma)$ as low as

83640,000 years for individual dated zircons. Schoene et al., (2019) sampled both coarse-grained

837 basalts and sedimentary beds between basalt flows that infrequently contain zircon-bearing

838 volcanic ashes. Age model 2 (M2) from Sprain et al., (2019)4 used what they describe as "high-

839 resolution ${ }^{40} \mathrm{Ar} /{ }^{39} \mathrm{Ar}$ plagioclase ages from the Deccan Traps that locate the $\mathrm{K} / \mathrm{Pg}$ and better refine 840 the timing and tempo of eruptive fluxes."

841 Schoene et al., (2020) $)^{80}$ describe a detailed comparision between the two age models for

842 Deccan Trap volcanism and show that the models give essentially consistent results. In Figure

843 S1, we illustrate the two model results. That figure shows theree major differences between M1

844 and M2 models. Relative to M2 model M1 indicates: (1) a 36 kyr younger, K/Pg boundary; (2)

845 a 58 kyr older a Bushe-Podladpur formation boundary; and (3) that the yougest sample in the

846 Mahabaleshwar formation is $~ 168$ kyr older. However, these finer differences wouldn't change

847 the first order observation that the onset of global warming at $66.4 \mathrm{Ma}$ is about 360 kyrs prior

848 to the onset of $73 \%$ of total volume of Deccan Traps eruptions at the Bushe-Podladpur formation 849 boundary. 
a. age model M1 (Schoene et al., 2019)

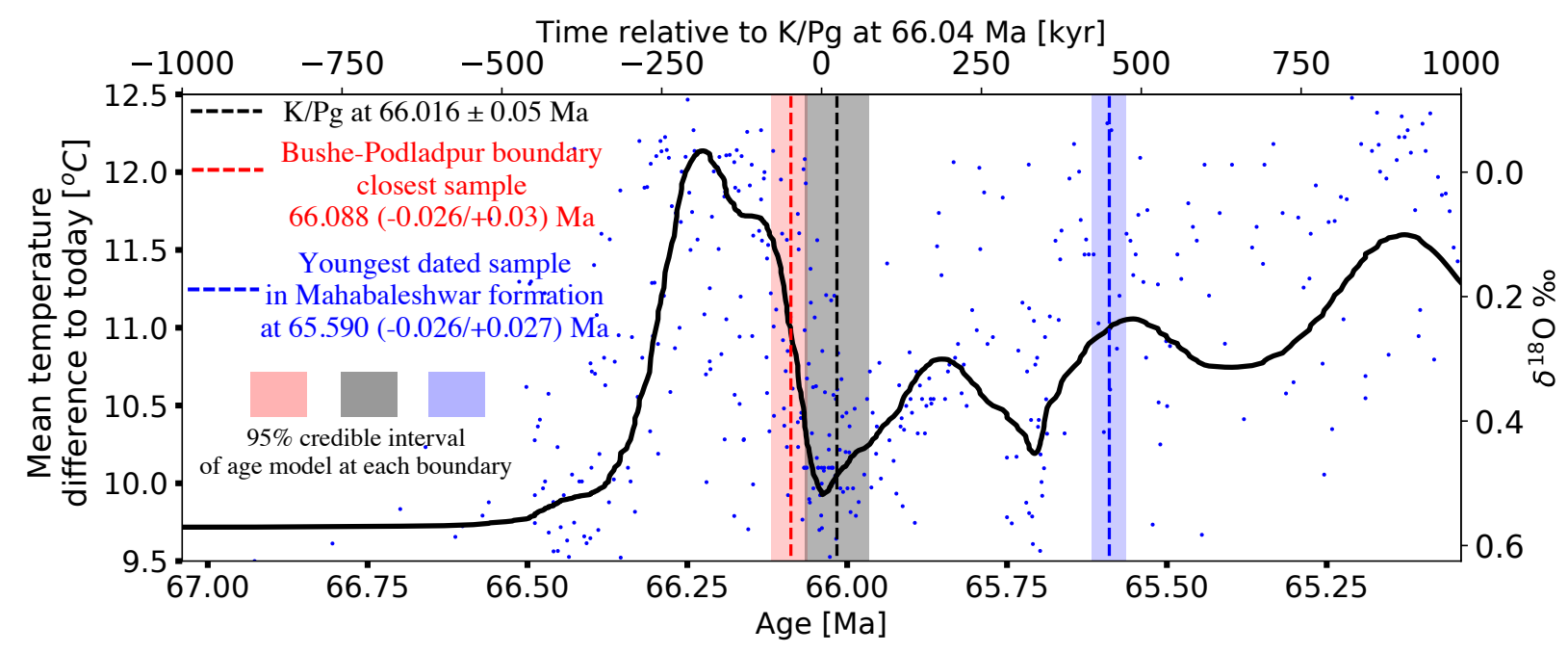

b. age model M2 (Sprain et al., 2019)

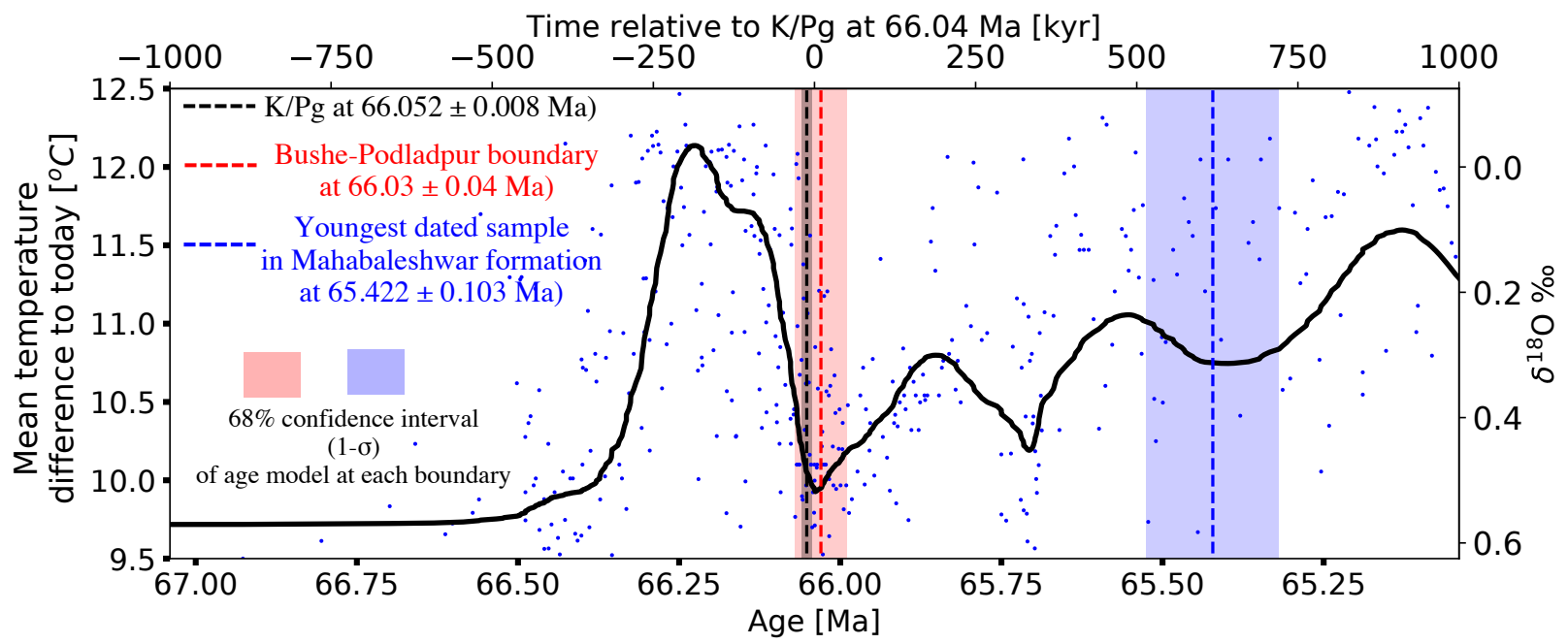

Supplementary Figure S1. Comparision between age models M1 and M2 for Deccan Traps and K/Pg climate

variations. Both age models of Deccan Traps use Richards et al., (2015) ${ }^{11}$ flood basalt volume model in which the 3 formations (Poladpur, Ambenali and Mahabaleshwar) in the younger Wai subgroup comprise a volume of about $439,000 \mathrm{~km}^{3}, 73 \%$ of total volume $\left(602,700 \mathrm{~km}^{3}\right)$ of Deccan Traps. Both age models are overlapped with global climate change data from Hull et al., (2020)7, which use 66.04 Ma as K/Pg boundary from D'Hondt and Lindiger $(1994)^{81} . \Delta$ Temperature in Fig.1 of Hull et al., (2020) is the global temperature change relative to the temperature at $\mathrm{K} / \mathrm{Pg}$ boundary. We assume a temperature of $10.1^{\circ} \mathrm{C}$ at $66.040242 \mathrm{Ma}$ for temperature at the $\mathrm{K} / \mathrm{Pg}$ boundary provided by Table S4 of Hull et al., (2020) citing Li and Keller (1998). This allow us to calculate temperature 
data detailed description. We filter data from Table S4 of Hull et al., (2020) with a Butterworth low pass filter

861 (scipy.signal.butter) with the order of the filter $\mathrm{N}=6$ and the critical frequency parameter $\mathrm{Wn}=0.01$. The $\delta^{18} O$ is

862 converted from the temperature data using equations from Table S7 of Westerhold et al., (2020). a): age model M1

863 from Schoene et al., 2019. The black dashed-line is the model prefered K/Pg boundary at $66.016 \pm 0.05$ Ma with 95\%

864 credible interval indicated with the gray rectangle. The red dashed-line is the model prefered Bushe-Poladpur

865 formation boundary at $66.088(-0.026 /+0.03)$ Ma with 95\% credible interval indicated with the red rectangle. The

866 blue dashed-line is the model prefered youngest dated sample in Mahabaleshwar formation at $65.590(-0.026 /+0.027)$

867 Ma with 95\% credible interval indicated with the blue rectangle. b): age model M2 from Sprain et al., 2019. The

868 black dashed-line is the model prefered $\mathrm{K} / \mathrm{Pg}$ boundary at $66.052 \pm 0.008 \mathrm{Ma}$. The red dashed-line is the model

869 prefered Bushe-Poladpur formation boundary at $66.03 \pm 0.04$ Ma with 1- $\sigma(68 \%)$ confidence interval indicated with

870 the red rectangle. The blue dashed-line is the model prefered youngest dated sample in Mahabaleshwar formation at

$87165.422 \pm 0.103$ Ma with 1- $\sigma(68 \%)$ confidence interval indicated with the blue rectangle.

872

873

The Schoene et al., (2019) M1 age model resolves a finer eruption flux that has four

874 separate pulses including one that is 20 to $60 \mathrm{kyr}$ prior to the impact (K/Pg boundary). However,

875 according to Hull et al., (2020), when assuming an eruption flux according to the M1 flux model

876 from Schoene et al., (2019), which is the case 3 (punctuated) of Hull et al., 2020 climate

877 modeling, the modeled climate response is not able to reproduce the observed globally compiled

878 climate change data. Hull et al., (2020) suggest that "if the M1 model from Schoene is correct

879 with a large pulse of emplacement 20 to $60 \mathrm{kyr}$ before the impact (K/Pg boundary), then most

$880 \mathrm{CO}_{2}$ outgassing must have preceded lava emplacement by several hundred thousand years. This

881 would be before the eruption of the most voluminous stages of Deccan volcanism (i.e. before the

882 Wai group starting at Bushe-Podladpur formation boundary)" 
a Deccan Traps and $\mathrm{K} / \mathrm{Pg}$ Global Warming

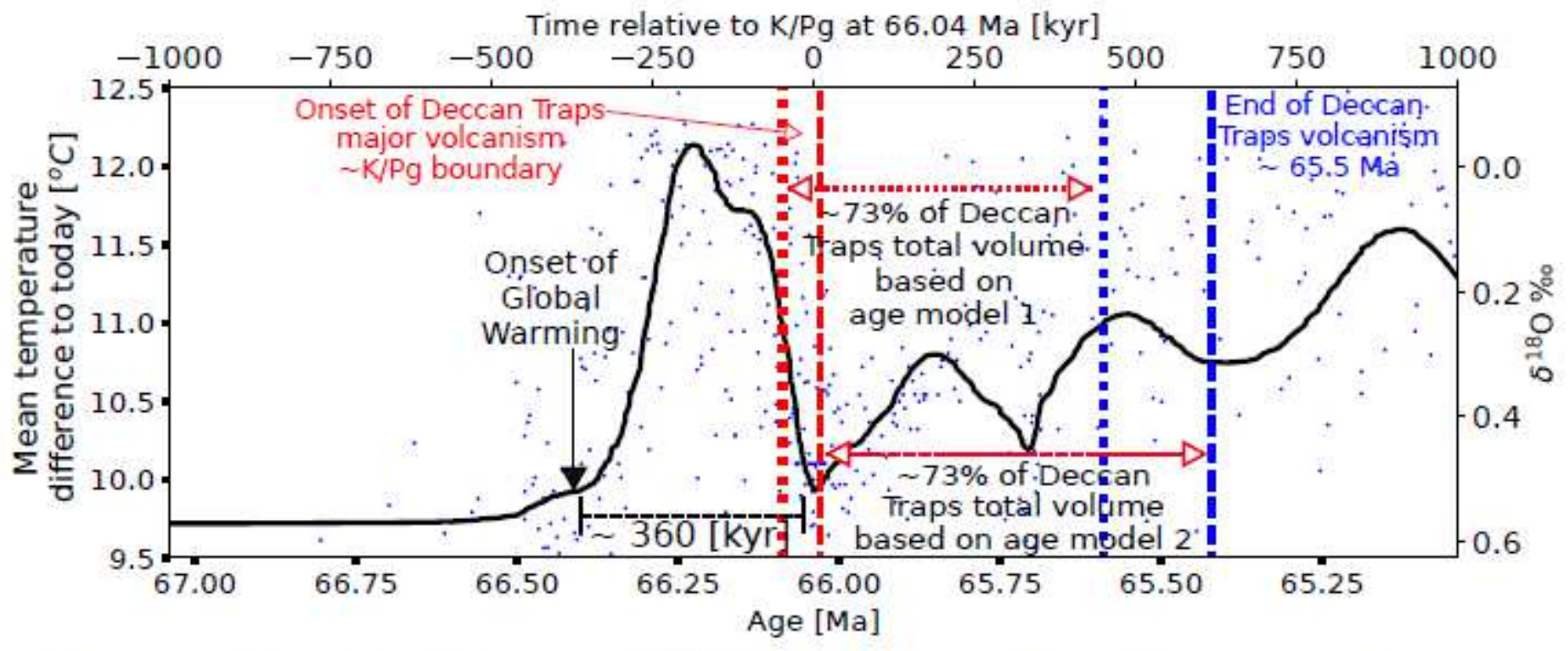

b Columbia River Basalt Group (CRBG) and Miocene Climate Optimum (MCO)

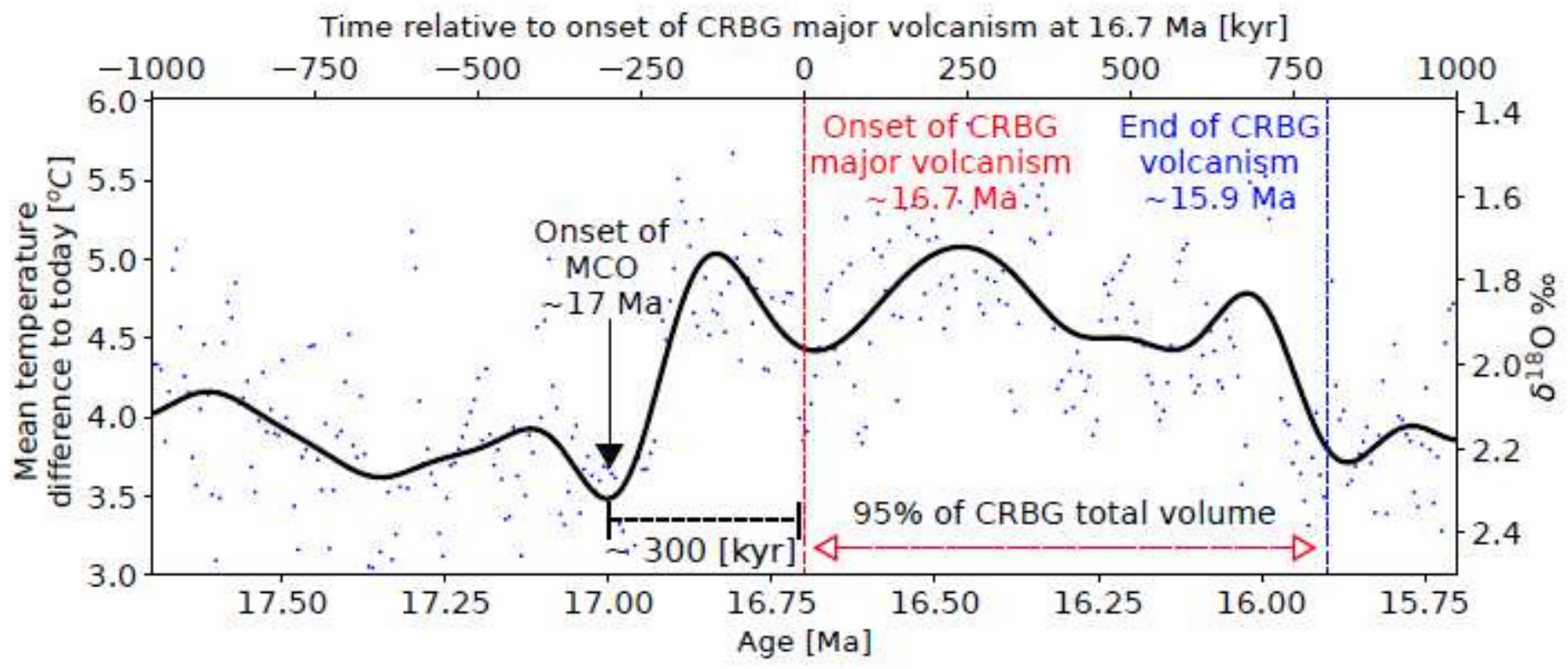

\section{Figure 1}

Global temperature variations within $1000 \mathrm{kyr}$ of the approximate onset of the main volcanic phases of the Deccan Traps ${ }^{\wedge} 4,5$ and Columbia River Basalt Group ${ }^{\wedge} 6$ LIPs. Black lines result from low-pass filtering of the blue dots $\mathbb{\nabla}^{\wedge} 18 \rrbracket$ data and estimated temperature variations with time ${ }^{\wedge} 7-9$. The age of onset and ending of the main Deccan volcanic phase for two basalt dating methods are indicated by the pairs of vertical dashed lines. Vertical arrows indicate that the onset of global warming for each case precedes 
the main volcanic phase by $\sim 300 \mathrm{kyr}$. Details of the age models and temperature estimates are described in the supplement.
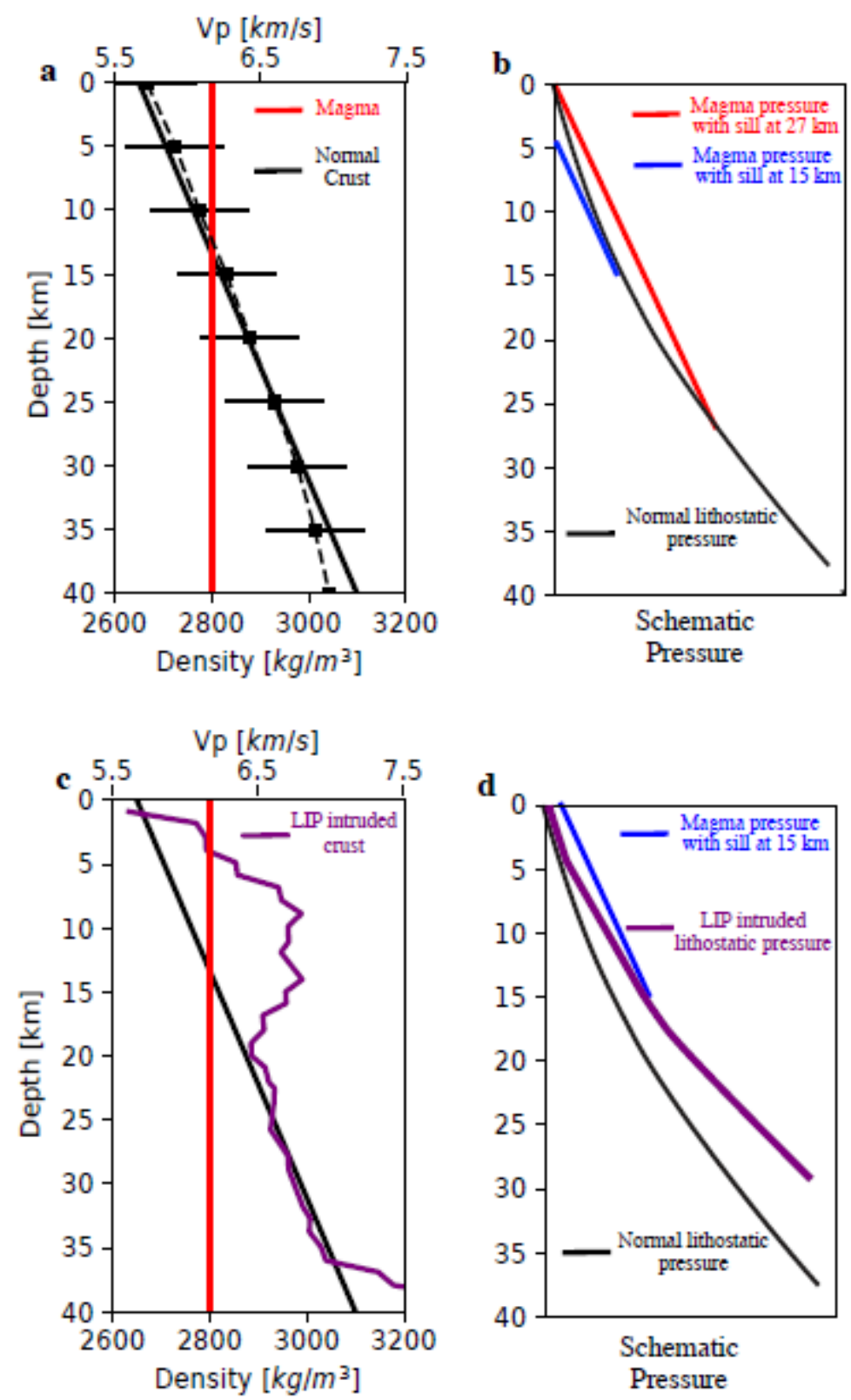

\section{Figure 2}

Illustrations of relations between seismic velocities, densities and pressures in typical continental crust $(a, b)$ and the crust under part of the Deccan LIP $(c, d)$. a, shows average continental P-wave velocity (dashed) from ref ^ 33 with density assuming a linear relation between velocity and density. Solid lines show densities assumed in the model. Magma density is from ref. ^34. b, black line shows lithostatic pressure for the density structure given by solid line in a. Red line shows static pressure in a column of magma just reaching the surface while blue shows the same for a column of magma with lithostatic pressure at $15 \mathrm{~km}$ depth. c, P-wave velocity and density profiles beneath Deccan Traps are converted from refs. ${ }^{\wedge} 18,19$ using a Vs to Vp relationship (ref. ${ }^{\wedge} 35$ ). d, Purple line shows lithostatic pressure for the 
purple density from c. Blue line shows that for densified crust a sill as shallow as $15 \mathrm{~km}$ depth can supply eruptions. Schematic pressure is shown so the difference between lithostatic pressure and magma pressure is visible.

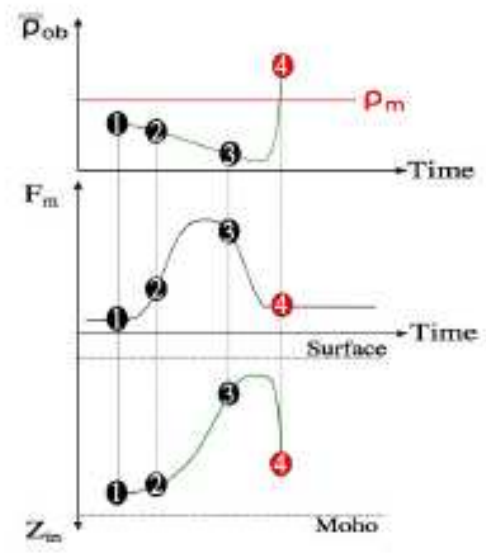

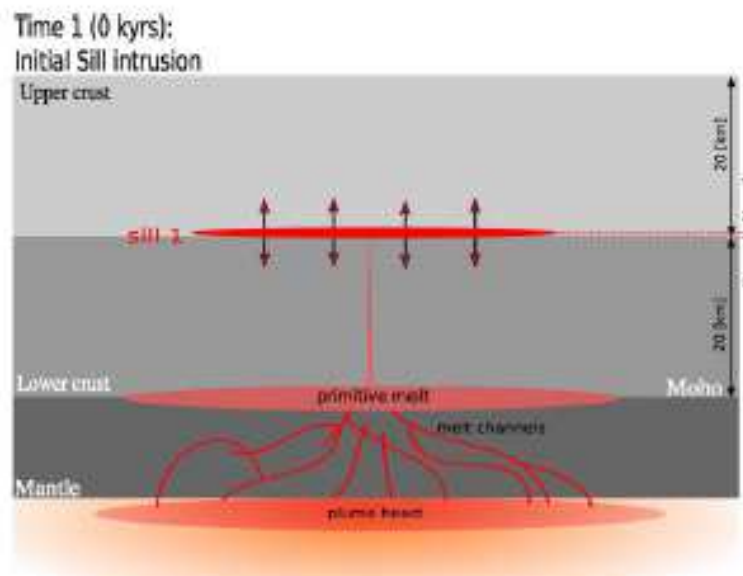

Time 2 (100 kyrs):

Following sills intruding into a warmed-up upper crust

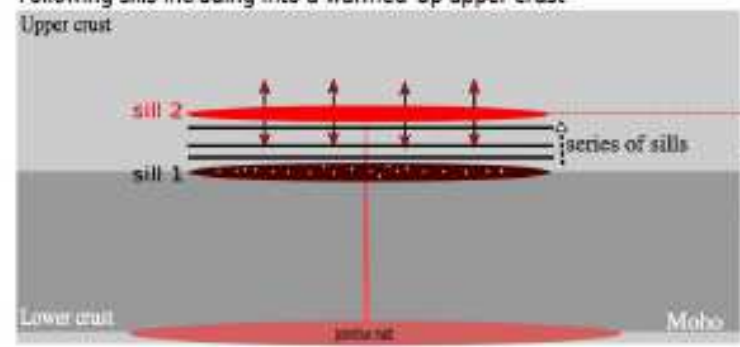

Time 3 (200 kyrs):

Magma flux peaks \& Hydrothermal cooling increases
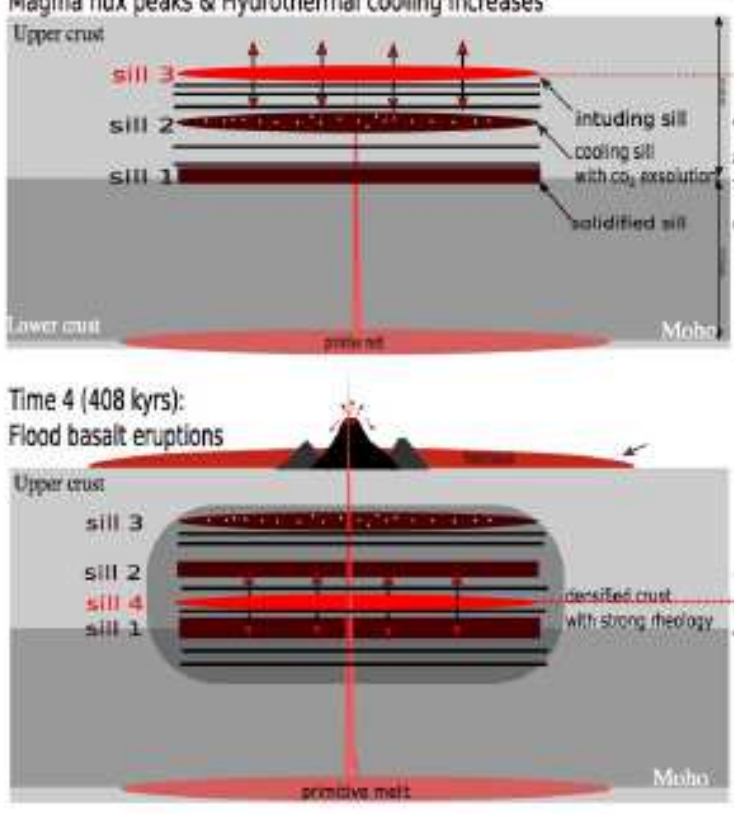
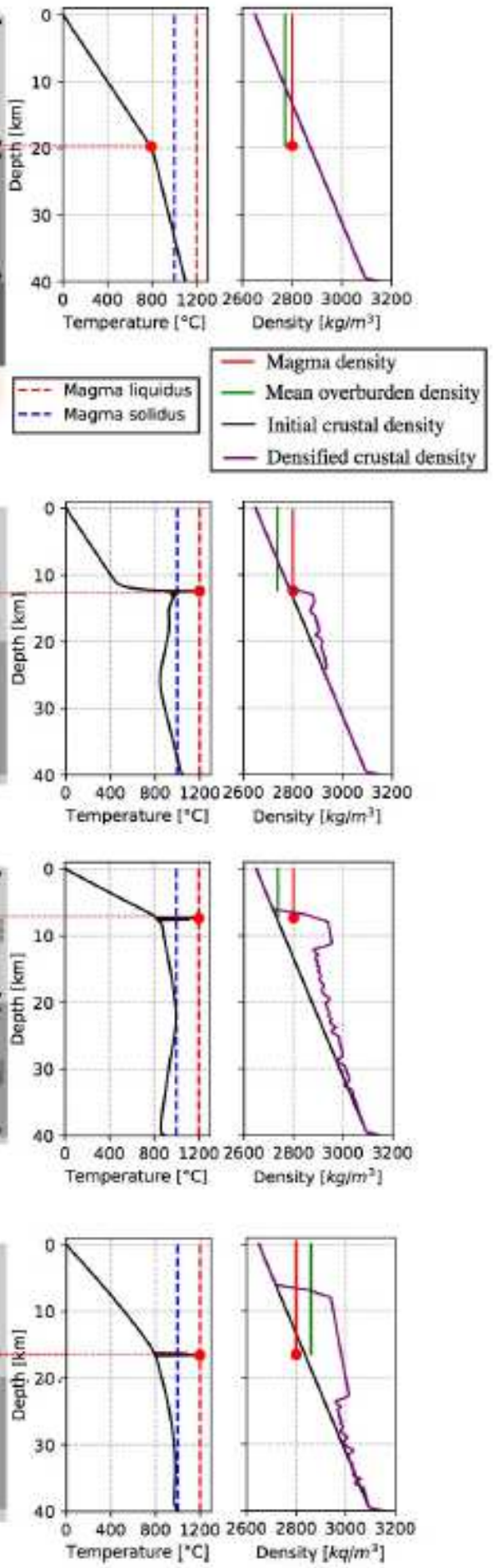

\section{Figure 3}

One dimensional thermo-mechanical model results showing the changes in crustal temperatures and densities due to evolving sill intrusions. 『in is intrusion depth, $₫ \mathrm{~m}$ is magma flux, / \ob is average density 
of the overburden and $₫ \mathrm{~m}$ is magma density. The numbers 1 to 4 correspond to the stages of the system developments described in the text.

Modeled Results for

Deccan Trap and Climate around $\mathrm{K} / \mathrm{Pg}$
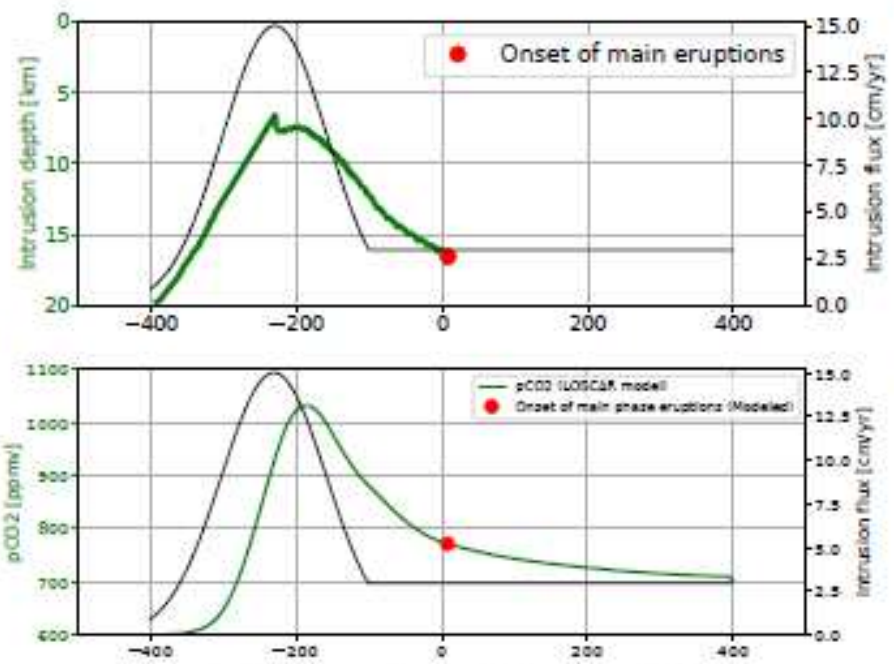

c

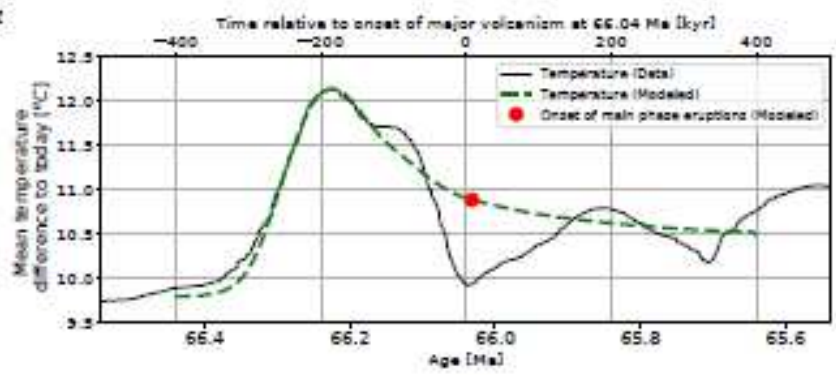

Modeled Results for $\mathrm{CRBG}$ and $\mathrm{MCO}$

d

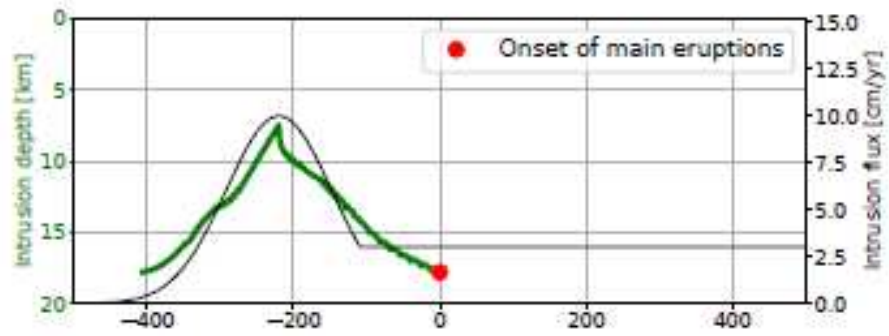

e

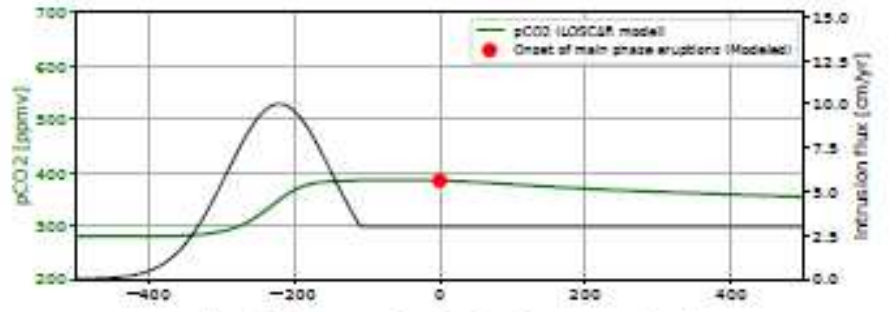

f

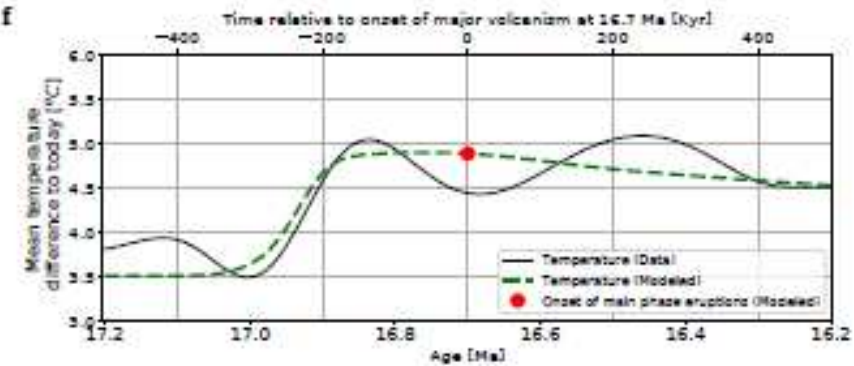

Figure 4

Time series of modeled global temperature variations and onsets of main-phase eruptions of Deccan Traps (abc) and CRBG (def). a,d sill intrusion depth and the timing of transition from mostly intrusion to major phase of extrusion, predicted by the thermo-mechanical model described in the Methods, given the indicated melt flux with time. CRBG case (d) has a lower peak flux of $10 \mathrm{~cm} / \mathrm{yr} \mathrm{b}, \mathrm{e}$, global averaged atmospheric $\mathrm{CO} 2$ concentration with time predicted by the LOSCAR climate model. c,f global temperature change predicted by the LOSCAR model on top of climate data (Fig.1) and with the modeled timing of onsets of main-phase eruptions.

\section{Supplementary Files}

This is a list of supplementary files associated with this preprint. Click to download.

- Video1densityDeccan.mp4

- Video2pressuresDeccan.mp4

- Video3viscosityDeccan.mp4 
- Video4FluxSillDepthTPBKDeccan.mp4

- Video5densityCRB.mp4

- Video6pressuresCRB.mp4

- Video7viscosityCRB.mp4

- Video8TandMBKPCRB.mp4 